\title{
Deranged Calcium Signaling and Neurodegeneration in Spinocerebellar Ataxia Type 3
}

\author{
Xi Chen, ${ }^{1}$ Tie-Shan Tang, ${ }^{1}$ Huiping Tu, ${ }^{1}$ Omar Nelson, ${ }^{1}$ Mark Pook,,${ }^{3}$ Robert Hammer, ${ }^{2}$ Nobuyuki Nukina, ${ }^{4}$ and \\ Ilya Bezprozvanny ${ }^{1}$ \\ Departments of ${ }^{1}$ Physiology and ${ }^{2}$ Biochemistry, University of Texas Southwestern Medical Center, Dallas, Texas $75390,{ }^{3}$ School of Health Sciences and \\ Social Care, Brunel University, Uxbridge, Middlesex UB8 3PH, United Kingdom, and ${ }^{4}$ Laboratory for Structural Neuropathology, RIKEN Brain Science \\ Institute, Saitama 351-0198, Japan
}

Spinocerebellar ataxia type 3 (SCA3), also known as Machado-Joseph disease (MJD), is an autosomal-dominant neurodegenerative disorder caused by a polyglutamine expansion in ataxin-3 (ATX3; MJD1) protein. In biochemical experiments, we demonstrate that mutant ATX3 ${ }^{\exp }$ specifically associated with the type 1 inositol 1,4,5-trisphosphate receptor (InsP $\left.{ }_{3} \mathrm{R} 1\right)$, an intracellular calcium $\left(\mathrm{Ca}^{2+}\right)$ release channel. In electrophysiological and $\mathrm{Ca}^{2+}$ imaging experiments, we show that $\mathrm{InsP}_{3} \mathrm{R} 1$ was sensitized to activation by Ins $\mathrm{P}_{3}$ in the presence of mutant ATX3 ${ }^{\text {exp }}$. We found that feeding SCA3-YAC-84Q transgenic mice with dantrolene, a clinically relevant stabilizer of intracellular $\mathrm{Ca}^{2+}$ signaling, improved their motor performance and prevented neuronal cell loss in pontine nuclei and substantia nigra regions. Our results indicate that deranged $\mathrm{Ca}^{2+}$ signaling may play an important role in SCA3 pathology and that $\mathrm{Ca}^{2+}$ signaling stabilizers such as dantrolene may be considered as potential therapeutic drugs for treatment of SCA3 patients.

Key words: calcium signaling; neurodegeneration; ataxin-3; spinocerebellar ataxia type 3; SCA3; Machado-Joseph disease; MJD1; transgenic mouse; stereology; dantrolene

\section{Introduction}

Spinocerebellar ataxia type 3 (SCA3), also known as MachadoJoseph disease (MJD), is an autosomal-dominant neurodegenerative disorder that belongs to a group of polyglutamine [poly(Q)]-expansion diseases (Cummings and Zoghbi, 2000; Gusella and MacDonald, 2000; Zoghbi and Orr, 2000). The symptoms of SCA3 include gait ataxia, dysarthria, dysmetria, hyperreflexia, dystonia, and ophthalmoplegia (Coutinho and Andrade, 1978). The brain regions most affected in SCA3/MJD are dentate and pontine nuclei, internal portion of globus pallidus, subthalamic nucleus, substantia nigra (SN), and spinocerebellar tracts (Stevanin et al., 2000). At molecular level, the cause of $\mathrm{SCA3}$ is a poly $(\mathrm{Q})$ expansion in the C-terminal of ataxin-3

\footnotetext{
Received Aug. 15, 2008; accepted 0ct. 7, 2008.

This work was supported by The McKnight Neuroscience of Brain Disorders Award, Robert A. Welch Foundation National Ataxia Foundation, Ataxia MJD Research Project, and National Institute of Neurological Disorders and Stroke (NINDS) Grants R01NS38082 and R01NS056224 (I.B.); the Division of Basic Science Training Grant and National Institutes of Health (NIH) Predoctoral Fellowship Award for Minority Students F31 AG031692 (0.N.); Ataxia UK and Ataxia MJD Research Project (M.P.); and Ministry of Education, Culture, Sports, Science, and Technology of Japan Grant-in-Aid 17025044 (N.N.). The monoclonal anti-InsP ${ }_{3} \mathrm{R} 1$ antibody L24/18 was developed and obtained from the University of California at Davis/NINDS/National Institute of Mental Health NeuroMab Facility supported by NIH Grant U24NS05060. I.B. is a holder of Carla Cocke Francis Professorship in Alzheimer's Research. We thank Xiangme Kong, Tianhua Lei, and Huarui Liu for help with maintaining the SCA3 mouse colony; Janet Young and Leah Benson for administrative assistance; Noelle Williams for assistance with the measurements of dantrolene concentrations; Lisa Monteggia, Jenny Hsieh, Malu Tansey, Keith Tansey, and Don Cooper for help and advice with behavioral and stereological experiments; Henry Paulson for the gift of human-specific ATX3 polyclonal antibody; and Andrew Marks for the gift of rat RyanR1 expression plasmid.

Correspondence should be addressed to Dr. llya Bezprozvanny at the above address. E-mail: ilya.bezprozvanny@utsouthwestern.edu.

H. Tu's present address: Merck Research Laboratories, P.0. Box 2000, Rahway, NJ 07065-0900.

D0I:10.1523/JNEUROSCI.3909-08.2008

Copyright $\odot 2008$ Society for Neuroscience $\quad 0270-6474 / 08 / 2812713-12 \$ 15.00 / 0$
}

(ATX3; MJD1) protein (Kawaguchi et al., 1994; Paulson et al., 1997a). The ataxin-3 is a $43 \mathrm{kDa}$ cytosolic protein that contains $\mathrm{N}$-terminal Josephin domain and two ubiquitin-interactions motifs (Scheel et al., 2003; Nicastro et al., 2005). Poly(Q)expansion occurs in C-terminal region of ataxin-3 that does not contain any known functional motifs. Despite intense efforts, the cellular pathogenic mechanism of SCA3 remains unclear.

Huntington's disease (HD) is another member of poly $(\mathrm{Q})$ expansion disease family, which is caused by a poly(Q)expansion in the context of Huntingtin protein $(\mathrm{Htt})$. In our previous studies, we demonstrated that mutant $\mathrm{Htt}^{\exp }$ protein specifically binds to and activates type 1 inositol 1,4,5trisphosphate receptor $\left(\mathrm{InsP}_{3} \mathrm{R} 1\right)$ (Tang et al., 2003). From these results, we proposed that deranged $\mathrm{Ca}^{2+}$ signaling may play an important role in HD pathogenesis (Bezprozvanny and Hayden, 2004). These ideas were supported by our studies with primary neuronal cultures from YAC128 HD mouse model (Tang et al., 2005; Wu et al., 2006). It is generally assumed that many poly(Q)expansion disorders share a common pathogenic mechanism (Cummings and Zoghbi, 2000; Gusella and MacDonald, 2000; Zoghbi and Orr, 2000). Here, we set out to investigate whether abnormal $\mathrm{Ca}^{2+}$ signaling also plays a role in SCA3 pathogenesis. In a series of biochemical and functional experiments, we investigated interactions between ataxin- 3 and $\mathrm{Ins}_{3} \mathrm{R} 1$. We extended these findings to the analysis of SCA3-YAC-84Q mouse model. Obtained results suggested that deranged neuronal $\mathrm{Ca}^{2+}$ signaling plays a significant role in SCA3 pathology; calcium signaling stabilizers may be considered as potential therapeutic drugs for the treatment of SCA3 patients. 


\section{Materials and Methods}

SCA3 mouse colonies. Generation of SCA3-YAC-15Q and SCA3-YAC$84 \mathrm{Q}$ mice have been previously described (Cemal et al., 2002). For our studies, SCA3-YAC-84Q mouse was recreated by in vitro fertilization using C57BL/6 mouse strain egg and SCA3-YAC-84Q mouse frozen sperm. All the procedures involving mice were approved by Institutional Animal Care and Use Committee of University of Texas Southwestern, in accord with the National Institutes of Health Guidelines for the Care and Use of Experimental Animals.

Human primary fibroblast lines. Primary human fibroblasts (hF-SCA3) derived from a 38-year-old symptomatic SCA3 patient (subject GM06151) and the human fibroblasts (hFs) from healthy individual (subject GM02185C) were obtained from Coriell Cell Repositories (Coriell Institute for Medical Research).

In vitro binding experiments. Enhanced green fluorescent protein (EGFP)-ATX3-19Q, EGFP-ATX3-77Q, and EGFP-ATX3-127Q expression plasmids have been previously described (Wang et al., 2000). Glutathione $S$-transferase (GST)-IC10 expression plasmid (amino acids F2627-A2749 of rat Ins $\mathrm{P}_{3} \mathrm{R} 1$ ) has been previously described (Tang et al., 2003). GST and GST-IC10 proteins were expressed in the BL21 Escherichia coli strain and purified on glutathione-agarose beads. EGFPATX3-19Q/77Q/127Q proteins were expressed in HEK293 cells by calcium phosphate transfection. Forty-eight hours after transfection, HEK293 cells were collected with ice-cold PBS and solubilized for $30 \mathrm{~min}$ at $4^{\circ} \mathrm{C}$ in extraction buffer A [1\% 3-[(3-cholamidopropyl)dimethylammonio]-1-propanesulfonate (CHAPS), $137 \mathrm{~mm} \mathrm{NaCl}, 2.7$ mм KCl, $4.3 \mathrm{~mm} \mathrm{Na}_{2} \mathrm{HPO}_{4}, 1.4 \mathrm{~mm} \mathrm{KH}_{2} \mathrm{PO}_{4}$, pH 7.2, 5 mм EDTA, 5 mм EGTA, and protease inhibitors]. Extracts were clarified by centrifugation for $20 \mathrm{~min}$ at $100,000 \times \mathrm{g}$ and incubated for $1 \mathrm{~h}$ at $4^{\circ} \mathrm{C}$ with GST or GST-IC10 proteins. Beads were washed three times with extraction buffer A. Attached proteins were analyzed by Western blotting with antigreen fluorescent protein (GFP) monoclonal antibodies.

Full-length rat InsP ${ }_{3} \mathrm{R} 1$ (RT1)-encoding baculoviruses were previously described (Tu et al., 2002). The EGFP-ATX3-19Q, EGFP-ATX3$77 \mathrm{Q}$, and EGFP-ATX3-127Q proteins were transiently expressed in HEK293 cells as described above and solubilized in 1\% CHAPS. The mixture of RT1 and ataxin-3 containing lysates was precipitated with anti-InsP ${ }_{3} \mathrm{R} 1$ polyclonal antibody (T443) (Kaznacheyeva et al., 1998) attached to protein A-Sepharose beads and analyzed by Western blotting with anti-GFP monoclonal antibodies. Preimmune sera $(\mathrm{P} / \mathrm{S})$ were used in control immunoprecipitation experiments.

The full-length rat type 1 ryanodine receptor (RyanR1) expression plasmid was a kind gift from Dr. Andrew Marks (Columbia University, New York, NY). The RyanR1 expression plasmids were cotransfected with EGFP-ATX3-19Q and EGFP-ATX3-127Q plasmids into HEK293 cells. The lysates from transfected cells were extracted in 1\% CHAPS as described above, precipitated with anti-Atx3 monoclonal antibodies $1 \mathrm{H} 9$ (Millipore; MAB 5360) and analyzed by the Western blotting with antiRyanR monoclonal antibodies (Affinity BioReagents; MA3-925).

Planar lipid bilayer experiments. Single-channel recordings of recombinant InsP ${ }_{3} \mathrm{R} 1$ (RT1) were performed as previously described (Tang et al., 2003; Tu et al., 2005a,b) at $0 \mathrm{mV}$ transmembrane potential using 50 $\mathrm{mM} \mathrm{Ba}{ }^{2+}$ (trans) as a charge carrier. The cis-(cytosolic) chamber contained $110 \mathrm{~mm}$ Tris dissolved in HEPES, pH 7.35, $0.5 \mathrm{~mm} \mathrm{Na}_{2} \mathrm{ATP}, \mathrm{pCa}$ 6.7 (0.2 mm EGTA plus 0.14 mm $\mathrm{CaCl}_{2}$ ) (Bezprozvanny et al., 1991). Ins $\mathrm{P}_{3} \mathrm{R} 1$ were activated by addition of $100 \mathrm{~nm} \mathrm{InsP}_{3}$ (Alexis) to the cischamber as indicated in the text. Coding sequences of ATX3-19Q/77Q proteins were subcloned into pMAL2 bacterial expression vector (New England Biolabs). Maltose-binding protein (MBP), MBP-ATX3-19Q, and MBP-ATX3-77Q proteins were expressed in BL21 E. coli, purified on amylose resin (New England Biolabs) followed by gel filtration on Sephadex-10 column (AKTA FPLC; GE Healthcare). The proteins were dialyzed overnight against cis-recording buffer (110 mM Tris/HEPES, $\mathrm{pH}$ $7.35)$, and added in $1 \mu \mathrm{l}$ volume $(0.3 \mathrm{mg} / \mathrm{ml}$ protein with addition of 0.02 $\mathrm{mm}$ ruthenium red) directly to the cis-side of the bilayer containing Ins $\mathrm{P}_{3} \mathrm{R} 1$ without stirring. Exposure of $\mathrm{InsP}_{3} \mathrm{R} 1$ to the test proteins was terminated 2-3 min after addition by stirring the cis-chamber for $30 \mathrm{~s}$ (1:3000 dilution of test protein stocks). The $\mathrm{Ins}_{3} \mathrm{R} 1$ single-channel cur- rents were amplified (Warner OC-725), filtered at $1 \mathrm{kHz}$ by a low-pass eight-pole Bessel filter, digitized at $5 \mathrm{kHz}$ (Digidata 1200; Molecular Devices), and stored on computer hard drive and recordable optical discs. For off-line computer analysis (pClamp 6; Molecular Devices), currents were filtered digitally at $500 \mathrm{~Hz}$. For presentation of the current traces, data were filtered at $200 \mathrm{~Hz}$.

Coexpression and functional reconstitution of ATX3-RT1 to planar lipid bilayers. Full-length ATX3-19Q and ATX3-77Q constructs were subcloned into pFastBacl vector (Invitrogen). The ATX3-19Q and ATX3$77 \mathrm{Q}$ baculoviruses were generated and amplified using Bac-to-Bac system according to the instructions of the manufacturer (Invitrogen). Expression in Sf9 cells was confirmed by Western blotting with anti-Atx3 monoclonal antibodies $1 \mathrm{H} 9$. The Sf9 cells were coinfected with baculoviruses encoding InsP $\mathrm{P}_{3} \mathrm{R} 1$ (RT1) and ATX3-19Q or ATX3-77Q proteins. The microsomes prepared from coinfected Sf9 cells were solubilized in extraction buffer $\mathrm{A}$ and used in immunoprecipitation experiments with anti-InsP ${ }_{3} \mathrm{R} 1$ polyclonal antibodies (T443) (Kaznacheyeva et al., 1998) attached to protein A-Sepharose beads. The precipitated samples were analyzed by Western blotting with anti-Atx 3 monoclonal antibodies 1H9. The microsomes from the RT1:ATX3-19Q and RT1:ATX3-77Q coinfected Sf9 cells were fused to bilayers and the bilayer current recordings, and analysis was performed as described above.

$\mathrm{Ca}^{2+}$ imaging experiments. The rat medium spiny neuronal (MSN) cultures on poly-D-lysine (Sigma-Aldrich)-coated $12 \mathrm{~mm}$ round glass coverslips were established as previously described (Tang et al., 2003). The $5 \mu \mathrm{M}$ AraC (cytosine arabinoside) (Sigma-Aldrich) was added at 2-4 $\mathrm{d}$ in vitro (DIV) to inhibit glial cell growth. ATX3-19Q, ATX3-77Q, and ATX3-127Q expression plasmids in pcDNA3 vector were generated by subcloning from EGFP-ATX3 plasmids described above. At 20 DIV, the MSN cultures were transfected by the calcium phosphate method with EGFP-C3 plasmid (Clontech) or a 1:3 mixture of EGFP:ATX3 expression plasmids as indicated in the text. Forty-eight hours after transfection, the MSN neurons were loaded with $5 \mu \mathrm{M}$ fura-2 AM (Invitrogen) in artificial CSF (ACSF) (140 mm NaCl, $5 \mathrm{~mm} \mathrm{KCl,} 1 \mathrm{~mm} \mathrm{MgCl} 2,2 \mathrm{~mm} \mathrm{CaCl}_{2}, 10 \mathrm{~mm}$ HEPES, pH 7.3) for $45 \mathrm{~min}$ at $37^{\circ} \mathrm{C}$. For imaging experiments, the coverslips were mounted onto a recording/perfusion chamber (RC-26G; Warner Instruments) maintained at $37^{\circ} \mathrm{C}$ ( $\mathrm{PH} 1$; Warner Instruments), positioned on the movable stage of an Olympus IX-70 inverted microscope, and perfused with ACSF media by gravity flow. After GFP imaging, the coverslip was washed extensively with $\mathrm{Ca}^{2+}$-free ACSF (omitted $\mathrm{CaCl}_{2}$ from ACSF and supplemented with $100 \mu \mathrm{M}$ EGTA). In $\mathrm{Ca}^{2+}$ imaging experiments, the MSN cells were intermittently excited by 340 and $380 \mathrm{~nm}$ UV light (DeltaRAM illuminator; PTI) using a fura-2 dichroic filter cube (Chroma Technology) and $60 \times$ UV-grade oilimmersion objective (Olympus). The emitted light was collected by an IC-300 camera (PTI), and the images were digitized by ImageMaster Pro software (PTI). Baseline (6 min) measurements were obtained before bath application of $10 \mu \mathrm{M}$ 3,5-dihydroxyphenylglycine (3,5-DHPG) (Tocris) dissolved in $\mathrm{Ca}^{2+}$-free ACSF. The DHPG solutions were prewarmed to $37^{\circ} \mathrm{C}$ before application to MSNs. Images at 340 and $380 \mathrm{~nm}$ excitation wavelengths were captured every $5 \mathrm{~s}$ and shown as $340 / 380$ image ratios at time points as indicated. Background fluorescence was determined according to the recommendations of the manufacturer (PTI) and subtracted. Bradykinin (BK)-induced $\mathrm{Ca}^{2+}$ release was measured in primary human fibroblasts by following similar procedures as we previously described (Nelson et al., 2007).

Analysis of transgenic ATX3 expression. The expression and subcellular localization of ATX3 was performed as previously described for human samples (Paulson et al., 1997b). Ten-month-old SCA3-YAC-15Q mice and age-matched SCA3-YAC-84Q mice were terminally anesthetized by pentobarbital with the dosage of $60 \mathrm{mg} / \mathrm{kg}$ and perfused transcardially with $20 \mathrm{ml}$ of $0.9 \%$ saline followed by $100 \mathrm{ml}$ of fixative (4\% paraformaldehyde in $0.1 \mathrm{M}$ PBS, $\mathrm{pH}$ 7.4). The brains were removed from skull and postfixed with $4 \%$ paraformaldehyde in $0.1 \mathrm{M}$ PBS, pH 7.4, overnight at $4^{\circ} \mathrm{C}$, and then infiltrated in $20-30 \%(\mathrm{w} / \mathrm{v})$ sucrose in PBS at $4^{\circ} \mathrm{C}$ for $24-48 \mathrm{~h}$ until falling to the bottom. The brains were frozen on dry ice and cut to $30-\mu \mathrm{m}$-thick coronal sections using a Leica SM2000R sliding microtome. The brain sections were treated with $1 \%$ hydrogen peroxide $\left(\mathrm{H}_{2} \mathrm{O}_{2}\right)$ in PBS for $30 \mathrm{~min}$, blocked with normal goat serum (Vector 
Laboratories) diluted 1:100 in PBST (0.3\% Triton X-100) for $30 \mathrm{~min}$, and then stained with human-specific anti-ATX3 polyclonal antibodies (Paulson et al., 1997a) (1:5000 dilution; a kind gift from Dr. Henry Paulson, University of Michigan, Ann Arbor, MI) overnight at room temperature. After being washed with PBS three times for 10 min each time, the sections were stained with biotinylated goat anti-rabbit IgG reagent (Vector Laboratories) for $1 \mathrm{~h}$ at room temperature. After PBS washing three times for $10 \mathrm{~min}$ each time, the signals were amplified with Vectastain Elite ABC reagent (Vector Laboratories) prepared in PBST and then detected with DAB (3,3'-diaminobenzidine) substrate kit (Vector Laboratories). The immunohistochemical pictures were taken in bright field under Nikon $60 \times$ oil objective.

In parallel experiments, the sections from 12-month-old SCA3-YAC84Q mice and 14-month-old SCA3-YAC-15Q were stained with antiAtx3 monoclonal antibody clone 1H9 (1:1000 dilution; Millipore; MAB 5360 ), followed by biotinylated anti-mouse IgG reagent (1:250 dilution; Vector Laboratories) (M.O.M. kit). Signal was amplified with the ABC Elite kit (Vector Laboratories) and detected with diaminobenzidine (Vector Laboratories). The immunohistochemical pictures were taken as described above.

Brain immunoprecipitations. Brains of wild-type (WT) and SCA3YAC-84Q mice were collected out of skull. After cerebella were taken away, the brain samples were homogenized and solubilized at $4^{\circ} \mathrm{C}$ for $2 \mathrm{~h}$ in extraction buffer A (1\% CHAPS, $137 \mathrm{~mm} \mathrm{NaCl}, 2.7 \mathrm{~mm} \mathrm{KCl}, 4.3 \mathrm{~mm}$ $\mathrm{Na}_{2} \mathrm{HPO}_{4}, 1.4 \mathrm{~mm} \mathrm{KH} \mathrm{PO}_{4}$, pH 7.2, 5 mM EDTA, 5 mM EGTA, and protease inhibitors). The homogenates were cleared by $30 \mathrm{~min}$ centrifugation at 50,000 rpm in TL-100 and incubated with anti-Atx3 monoclonal antibodies 1H9 (Millipore; MAB 5360) attached to protein-A/G PLUS-Agarose (Santa Cruz Biotechnology) at $4^{\circ} \mathrm{C}$ for $3 \mathrm{~h}$. The resulting beads were washed with extraction buffer $\mathrm{A}$ and analyzed by Western blotting with anti-InsP ${ }_{3} \mathrm{R} 1$ monoclonal antibody (University of California at Davis/National Institute of Neurological Disorders and Stroke/ National Institute of Mental Health NeuroMab Facility; clone L24/18). One twenty-fifth of each immunoprecipitate (IP) lysate was loaded as input.

Drug delivery in mice. Dantrolene was delivered to mice by an approach that we used previously in tetrabenzine trial in YAC128-HD mice (Tang et al., 2007). Briefly, groups of wild-type and SCA3-YAC-84Q mice were fed with $100 \mu \mathrm{g}$ of dantrolene suspended in $50 \mu \mathrm{l}$ of PBS with $2 \%$ corn flour resulting in the dosage $5 \mathrm{mg} / \mathrm{kg}$. The control groups were fed with $2 \%$ corn flour in PBS. All mice were fed orally twice a week from 2 to 12 months of age. To determine the concentration of dantrolene in mouse brains, five wild-type mice of 2 months of age were fed with dantrolene for 2 months with the same dosage $(5 \mathrm{mg} / \mathrm{kg}$ ) and anesthetized $30 \mathrm{~min}$ after the last dantrolene feeding. The blood samples of five mice were harvested into a tube containing $50 \mu \mathrm{l}$ of ACD solution $(2.2 \mathrm{~g}$ of sodium citrate; $0.8 \mathrm{~g}$ of citric acid, monohydrate; $2.24 \mathrm{~g}$ of glucose, anhydrous dissolved in $\mathrm{dH}_{2} \mathrm{O}$ to the final volume $100 \mathrm{ml}$ ). After spinning the blood samples at $4^{\circ} \mathrm{C}, 10,000 \mathrm{rpm}$ for $10 \mathrm{~min}$, plasma was isolated and transferred to $-80^{\circ} \mathrm{C}$ immediately. The brains were collected at the same time and snap frozen in liquid nitrogen. The plasma and brain samples from each mouse were numbered and shipped on dry ice to the core facility of the Department of Biochemistry of University of Texas Southwestern for analysis by HPLC.

Motor coordination assessments in mice. The motor coordination experiments were performed as previously described for the tetrabenzine trial in YAC128-HD mice (Tang et al., 2007). The "beam walking" assay was performed using a home-made experimental setup. The $17 \mathrm{~mm}$ round plastic beam, $11 \mathrm{~mm}$ round plastic beam, and $5 \mathrm{~mm}$ square wood beam were used in our studies. At each time point, the mice were trained on beams for 3 consecutive days (four trials per day) to traverse the beam to the enclosed box. Once the stable baseline of performance was obtained, the mice were tested in three consecutive trials on 17 and $11 \mathrm{~mm}$ round plastic beams and $5 \mathrm{~mm}$ square wood beam, in each case progressing from the widest to the narrowest beam. The latency to traverse the middle $80 \mathrm{~cm}$ of each beam and the number of times the hindfeet slipped off each beam were recorded for each trial. For each measurement, the mean scores of the three trials for each beam were used in the analysis.

For the footprint test, the forepaws and hindpaws of the mice were coated with purple and green nontoxic paints, respectively. The mice were trained to walk along a $50-\mathrm{cm}$-long, $10-\mathrm{cm}$-wide, paper-covered runway (with 10-cm-high walls) into an enclosed box. All the mice were given three runs per day for 3 consecutive days. A fresh sheet of white paper was placed on the floor of the runway for each run. The footprint patterns were assessed quantitatively by the measurements of stride length and frontpaw/hindpaw overlap as we described previously (Tang et al., 2007).

Neuropathological assessments in mice. The neuropathological assessments were performed as previously described (Tang et al., 2007). After all the behavioral testings (13.5 month time point), the mice were terminally anesthetized by pentobarbital and perfused transcardially as described above. All brains were removed from skull, weighed, and transferred to postfixative ( $4 \%$ paraformaldehyde in $0.1 \mathrm{~m} \mathrm{PBS,} \mathrm{pH} \mathrm{7.4).} \mathrm{The}$ brains were processed and cut into $30-\mu \mathrm{m}$-thick coronal sections as described above. The coronal slices spaced $90 \mu \mathrm{m}$ apart throughout the pontine nuclei $(\mathrm{Pn})$ were stained with anti-NeuN monoclonal antibody (1:1000 dilution; Millipore). The coronal sections spaced $120 \mu \mathrm{m}$ apart throughout the SN were stained with anti-tyrosine hydroxylase (TH) monoclonal antibody (1:400 dilution; Millipore). Biotinylated antimouse IgG reagent was used in all the staining as the secondary antibodies (1:250 dilution; Vector Laboratories) (M.O.M. kit). Signal was amplified with an ABC Elite kit (Vector Laboratories) and detected with diaminobenzidine (Vector Laboratories). All quantitative stereological analyses were performed blindly with respect to the nature of slices (genotype and drug feeding) using Stereoinvestigator setup and software (MicroBrightField). For neuronal counting in Pn, the grid size was set to $250 \times 200 \mu \mathrm{m}$, and the counting frame size was $40 \times 40 \mu \mathrm{m}$. For neuronal counting in $\mathrm{SN}$, the grid size was set to $130 \times 100 \mu \mathrm{m}$, and the counting frame size was $50 \times 50 \mu \mathrm{m}$. The average slice thickness after histological processing was determined to be $22 \mu \mathrm{m}$.

Statistical data analysis. For comparison between two groups, ANOVA with post hoc testing was used to statistically analyze data.

\section{Results}

\section{Mutant ataxin- 3 specifically binds to Ins $\mathrm{P}_{3} \mathrm{R} 1$ in vitro}

To determine whether ATX ${ }^{\exp }$ behaves similar to $\mathrm{Htt}^{\exp }$ and also binds to the InsP ${ }_{3} \mathrm{R} 1 \mathrm{C}$-terminal region, we expressed EGFPATX3-19Q, EGFP-ATX3-77Q, and EGFP-ATX3-127Q proteins (Wang et al., 2000) in HEK293 cells and performed a series of GST pulldown experiments with bacterially expressed $\mathrm{InsP}_{3} \mathrm{R} 1$ C-terminal fragment GST-IC10 (amino acids F2627 to A2749 of rat Ins $\mathrm{P}_{3} \mathrm{R} 1$ ). The precipitated samples were analyzed by Western blotting with anti-GFP monoclonal antibodies. We found that GST-IC10, but not GST, specifically associated with GFP-ATX377Q and GFP-ATX3-127Q proteins (Fig. 1A). Similar to Htt (Tang et al., 2003), association of ataxin-3 with IC10 fragment was dependent on poly $(\mathrm{Q})$ expansion because wild-type EGFPATX3-19Q protein did not bind to GST-IC10 (Fig. 1A). In the next series of experiments, we tested the association of full-length Ins $\mathrm{P}_{3} \mathrm{R} 1$ with ataxin-3. In these experiments, we expressed fulllength rat Ins $\mathrm{P}_{3} \mathrm{R} 1$ (RT1) in Sf9 cells by baculoviral infection and solubilized recombinant $\mathrm{InsP}_{3} \mathrm{R} 1$ (RT1) in 1\% CHAPS. The EGFP-ATX3-19Q, EGFP-ATX3-77Q, and EGFP-ATX3-127Q proteins were transiently expressed in HEK293 cells as described above and solubilized in 1\% CHAPS. The mixture of RT1 and ataxin-3 containing lysates was precipitated with anti-Ins ${ }_{3} \mathrm{R} 1$ rabbit polyclonal antibodies (T443) (Kaznacheyeva et al., 1998) and analyzed by Western blotting with anti-GFP monoclonal antibodies. Preimmune sera $(\mathrm{P} / \mathrm{S})$ were used in control immunoprecipitation experiments. We found that full-length $\mathrm{Ins}_{3} \mathrm{R} 1$ associated with EGFP-ATX3-77Q and EGFP-ATX3-127Q mutant proteins, but not with the wild-type EGFP-ATX3-19Q protein (Fig. $1 B$ ). Thus, association of full-length $\mathrm{InsP}_{3} \mathrm{R} 1$ with ataxin-3 also depends on poly(Q)-expansion in ataxin-3 sequence. 

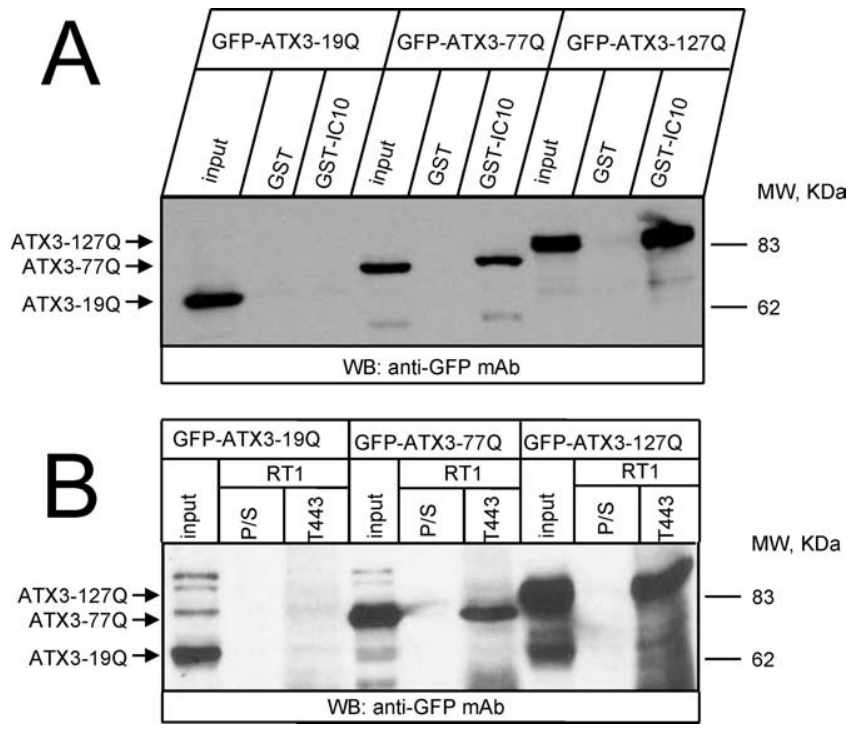

Figure 1. Biochemical association between mutant ataxin-3 and $\operatorname{lns}_{3}$ R1. $A$, GST/GST-IC10 pulldown experiments of EGFP-ATX3-19Q/770/1270 proteins from HEK293 cell extracts. Each input was $1 / 50$ of the pull-down lysate. $\boldsymbol{B}$, Immunoprecipitation of EGFP-ATX3/19Q/770/1270 from HEK293 cell lysates with full-length InsP $P_{3} R 1$ (RT1) expressed in Sf9 cells. Anti-InsP $P_{3} R 1$ polyclonal antibodies (T443) and corresponding control preimmune sera (P/S) were used for precipitation. The precipitated fractions on $\boldsymbol{A}$ and $\boldsymbol{B}$ were analyzed by Western blotting with anti-GFP monoclonal antibodies. The inputs were $1 / 50$ of the IP lysates.

In addition to $\mathrm{Ins}_{3} \mathrm{R}$ channels, $\mathrm{Ca}^{2+}$ release from neuronal endoplasmic reticulum can also be mediated by RyanR channels. The Ins $\mathrm{P}_{3} \mathrm{R}$ and RyanR have significant sequence homology in the C-terminal region, and it is possible that ATX $3^{\exp }$ also binds RyanR. To test this possibility, we cotransfected full-length rat RyanR1 expression plasmids together with EGFP-ATX3-19Q or EGFP-ATX3-127Q plasmids to HEK293 cells. The lysates from transfected cells were solubilized in 1\% CHAPS and immunoprecipitated with anti-Atx3 monoclonal antibodies. Western blotting with anti-RyanR monoclonal antibodies did not detect RyanR1 in precipitated samples (data not shown). Thus, we concluded that RyanR1 does not bind to ATX3-127Q and that association with $\mathrm{ATX} 3^{\exp }$ is specific for $\mathrm{Ins}_{3} \mathrm{R} 1$.

\section{Mutant ataxin-3 activates $\operatorname{Ins}_{3} \mathrm{R} 1$ in vitro}

To test functional effect of Atx3 ${ }^{\exp }$ on InsP ${ }_{3} \mathrm{R} 1$, the ATX3-19Q and ATX3-77Q full-length proteins were expressed in bacteria as MBP fusion proteins and purified by affinity chromatography followed by gel filtration. Obtained monomeric proteins were pure when analyzed by SDS-PAGE electrophoresis and Coomassie staining (Fig. $2 A$ ). The full-length InsP ${ }_{3} \mathrm{R} 1$ (RT1) was expressed in $\mathrm{Sf} 9$ cells by baculoviral infection and reconstituted into the planar lipid bilayers as we previously described (Tang et al., 2003; Tu et al., 2005a,b). The activity of recombinant $\operatorname{InsP}_{3} \mathrm{R} 1$ was induced by addition of $100 \mathrm{nM} \mathrm{InsP}_{3}$ to the cis-chamber (Fig. $2 B$, second trace; $D$, second trace). Addition of purified MBP or MBP-ATX3-19Q proteins had no effect on channel activity of InsP $\mathrm{P}_{3} \mathrm{R} 1$ in bilayers (Fig. $2 B$, third and fourth trace; $C$ ). In contrast, addition of MBP-ATX3-77Q protein induced pronounced activation of $\operatorname{InsP}_{3} \mathrm{R} 1$ (Fig. $2 D$, fourth trace; $E$ ).

In additional functional experiments, we generated baculoviruses encoding full-length ATX3-19Q and ATX3-77Q proteins. Efficient expression of ATX3-19Q and ATX3-77Q proteins in infected Sf9 cells was confirmed by Western blotting with antiataxin-3 monoclonal antibodies (Fig. $2 F$ ). The Sf9 cells were coinfected with RT1 baculoviruses encoding full-length $\operatorname{Ins}_{3} \mathrm{R} 1$ and ATX3-19Q or ATX3-77Q baculoviruses. The endoplasmic reticulum microsomes from coinfected Sf9 cells were solubilized in $1 \%$ CHAPS, precipitated with anti-InsP ${ }_{3} \mathrm{R} 1$ polyclonal antibodies, and probed with anti-ataxin-3 monoclonal antibodies. Consistent with the in vitro binding assay results (Fig. $1 B$ ), we found that the coexpressed full-length $\operatorname{Ins}_{3} \mathrm{R} 1$ associated with ATX3-77Q mutant protein, but not with the wild-type ATX3$19 \mathrm{Q}$ protein in the cellular context (supplemental Fig. 1, available at www.jneurosci.org as supplemental material). Microsomes prepared from Sf9 cells coinfected with RT1:ATX3-19Q or RT1: ATX3-77Q baculoviruses were fused to planar lipid bilayers as described above. Addition of $100 \mathrm{nM} \mathrm{InsP}_{3}$ induced only low levels of channel activity in Ins $\mathrm{P}_{3} \mathrm{R} 1$ coexpressed with ATX3-19Q (Fig. $2 G$, second trace; $H$ ), but resulted in dramatic activation of Ins $_{3} \mathrm{R} 1$ coexpressed with ATX3-77Q (Fig. $2 I$, second trace; $K$ ). Elevation of $\mathrm{InsP}_{3}$ concentration to $2 \mu \mathrm{M}$ increased activity of Ins $\mathrm{P}_{3} \mathrm{R} 1$ coexpressed with ATX3-19Q (Fig. 2G, third trace; $H$ ) but had no additional effect on activity of InsP ${ }_{3} \mathrm{R} 1$ coexpressed with ATX3-77Q (Fig. 2I, third trace; K). As a result of these bilayer reconstitution experiments, we concluded that association of $\mathrm{Atx} 3^{\exp }$ with $\mathrm{InsP}_{3} \mathrm{R} 1$ increases apparent affinity of Ins $\mathrm{P}_{3} \mathrm{R} 1$ to activation by $\mathrm{Ins}_{3}$, similar to our previous findings with $\mathrm{Htt}^{\exp }$ (Tang et al., 2003).

\section{Mutant ataxin-3 facilitates $\mathrm{Ins}_{3}$-induced $\mathrm{Ca}^{2+}$ release in cells}

To determine the functional effects of Atx $3^{\exp }$ on Ins $\mathrm{P}_{3} \mathrm{R} 1$ in cells, we transfected cultured rat striatal MSNs with ATX3-19Q, ATX3-77Q, and ATX3-127Q expression plasmids. To identify transfected cells, the ATX3 plasmids were cotransfected with EGFP-expressing plasmid. To stimulate InsP $\mathrm{P}_{3} \mathrm{R} 1$-mediated $\mathrm{Ca}^{2+}$ release, we challenged fura-2-loaded MSNs with $10 \mu \mathrm{M}$ DHPG, a specific mGluR1/5 receptor agonist. The local $\mathrm{Ca}^{2+}$ concentration in these experiments was estimated from the ratio of fura-2 signals at 340 and $380 \mathrm{~nm}$ excitation wavelengths as shown by pseudocolor images (Fig. 3A). The transfected cells were identified by GFP imaging (Fig. $3 A$, first column) before collecting $\mathrm{Ca}^{2+}$ imaging data.

Ten micromolar DHPG corresponds to a threshold concentration for mGluR $1 / 5$ receptor activation in MSNs, and only a small response to DHPG application at this concentration was observed in control MSNs transfected with EGFP plasmid alone (Fig. 3A, first row; $B, C$ ) and in MSNs transfected with ATX319Q plasmid (Fig. $3 A$, second row; $D, E$ ). In contrast, significant response to $10 \mu \mathrm{M}$ DHPG was observed in MSNs transfected with ATX3-77Q plasmid (Fig. 3A, third row; $F, G$ ). Even stronger response to DHPG was observed in MSNs transfected with ATX3127Q plasmid (Fig. $3 A$, fourth row; $H, I$ ). On average, after the addition of $10 \mu \mathrm{M}$ DHPG, the peak 340/380 ratios were significantly $(p<0.01)$ higher than basal 340/380 ratios in ATX3-77Q and ATX3-127Q transfected neurons, but not in ATX3-19Q and EGFP-only transfected neurons (Fig. $3 K$ ). Thus, we concluded that overexpression of ATX ${ }^{\exp }$ mutant protein, but not of ATX3 wild-type protein, sensitizes $\mathrm{InsP}_{3}$-sensitive $\mathrm{Ca}^{2+}$ stores in cultured neurons.

To further investigate functional effects of ATX $3^{\exp }$ on $\mathrm{Ca}^{2+}$ signaling in cells and to establish the relevance of our results for human disease, we performed a series of fura- $2 \mathrm{Ca}^{2+}$ imaging experiments with primary human fibroblasts from a healthy individual (hF) and a symptomatic SCA3 patient with 74Q expansion in ataxin-3 gene (hF-SCA3) (Fig. 4A). We discovered that application of $300 \mathrm{~nm} \mathrm{BK}$, an agonist of $\mathrm{Ins}_{3}$-coupled receptor, 
Table 1. Dantrolene trial in SCA3-YAC-84Q mice

\begin{tabular}{|c|c|c|c|c|c|c|c|c|}
\hline Group no. & Group name & No. of female mice & Mouse genotype & Single dose (2/week) (50 $\mu \mathrm{l})$ & $\begin{array}{l}\text { Drug dosage } \\
\left(\mathrm{mg} \cdot \mathrm{kg}^{-1} \cdot 3 \mathrm{~d}^{-1}\right)\end{array}$ & $\begin{array}{l}\text { Brain weight } \\
\text { (g) }\end{array}$ & Pn counts & SN-TH counts \\
\hline 1 & WT-Ctrl & 10 & WT & $50 \mu \mathrm{l}$ of PBS & PBS & $0.500 \pm 0.008$ & $43,368 \pm 1811$ & $11,026 \pm 284$ \\
\hline 2 & WT-Dan & 7 & WT & $100 \mu \mathrm{g}$ of dantrolene & $5 \mathrm{mg}$ of dantrolene & $0.501 \pm 0.004$ & $43,659 \pm 2203$ & $11,202 \pm 254$ \\
\hline 3 & SCA3-Ctrl & 8 & SCA3-YAC-84Q & $50 \mu \mathrm{l} \mathrm{of} \mathrm{PBS}$ & PBS & $0.451 \pm 0.007$ & $37,021 \pm 1000$ & $9384 \pm 250$ \\
\hline 4 & SCA3-Dan & 10 & SCA3-YAC-84Q & $100 \mu \mathrm{g}$ of dantrolene & $5 \mathrm{mg}$ of dantrolene & $0.470 \pm 0.007$ & $43,642 \pm 1725$ & $10,699 \pm 239$ \\
\hline
\end{tabular}

Four groups of mice were tested in our experiments. At 2 months of age, WT and 840 mice were divided into two groups each, and drug treatment was initiated. The group number, group name, number and genotype of mice in each group, and dose of single drug treatment (twice/week) are shown for each group. Also shown is the estimated drug dosage in milligrams per kilogram of body weight. The results of neuroanatomical analysis are shown for each group. The average brain weight, Pn neuronal counts, and SN-TH neuronal counts are shown as mean \pm SEM.
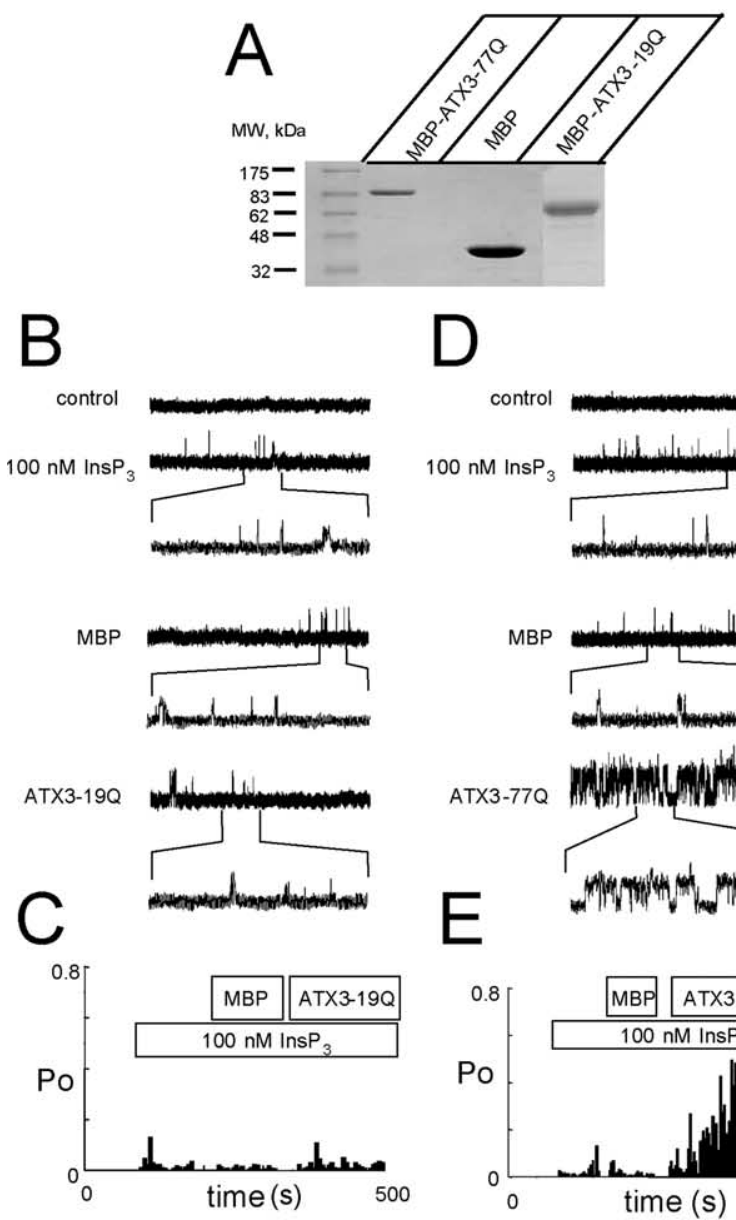
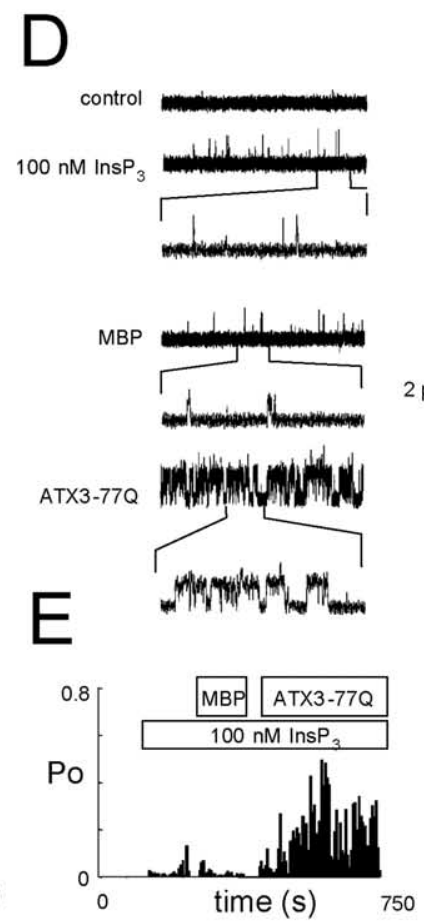

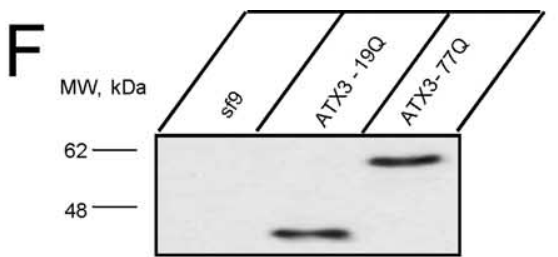

G

$\mathrm{RT} 1+\mathrm{ATX3-19Q}$

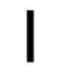

RT1+ATX3-77Q
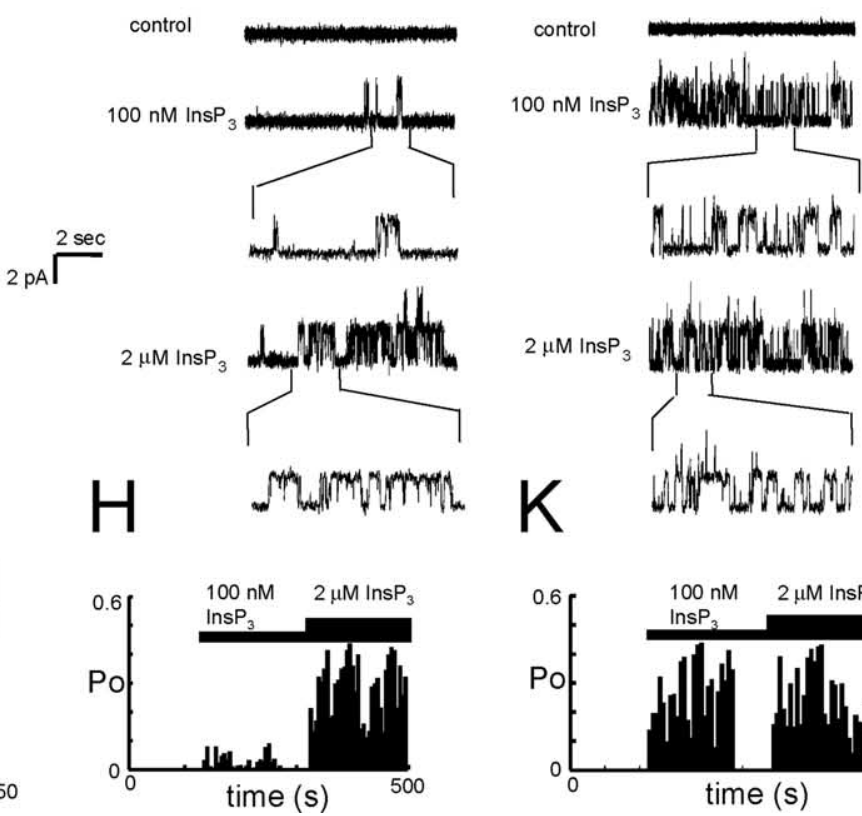

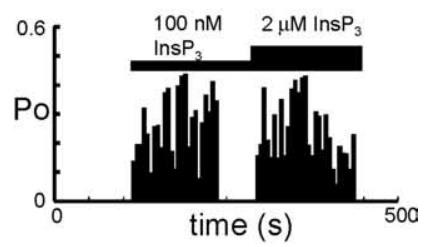

Figure 2. Mutant ataxin-3 sensitizes Ins $P_{3} R 1$ to the activation by InsP $P_{3}$ in bilayers. $A, M B P, M B P-A T X 3-19 Q$, and MBP-ATX3-770 were expressed in bacteria, purified and analyzed by SDS-PAGE electrophoresis and Coomassie staining. The blot of MBP-ATX3-190 was from a different blot. B, D, Effects of MBP, MBP-ATX3-19Q, and MBP-ATX3-77Q on the activity of recombinant InsP ${ }_{3} R 1$ in planar lipid bilayers at $100 \mathrm{~nm} \operatorname{Ins}_{3}$. Each current trace corresponds to $10 \mathrm{~s}$ ( $2 \mathrm{~s}$ for expanded traces) of current recording for the same experiment. $C, E$, The average open probability $\left(P_{0}\right)$ of Ins $P_{3} R 1$ at $100 \mathrm{~nm}$ InsP ${ }_{3}$ in the presence of MBP, MBP-ATX3-19Q, and MBP-ATX3-77Q. The average $P_{0}$ was calculated for a $5 \mathrm{~s}$ window of time and plotted for the duration of an experiment. The times of Ins ${ }_{3}$, MBP, MBP-ATX3-19Q, and MBP-ATX3-77Q additions are shown above the $P_{0}$ plot. Data from the same experiment are shown on $\boldsymbol{B}$ and $\boldsymbol{C}$, and $\boldsymbol{D}$ and $\boldsymbol{E}$. Similar results were obtained in at least three independent experiments with MBP-ATX3-19Q and MBP-ATX3-77Q. F, Microsomes from Sf9 cells coinfected with RT1 and ATX3-19Q or ATX3-77Q baculoviruses were blotted with anti-ataxin-3 monoclonal antibodies. G, $I$, Activity of InsP ${ }_{3} R 1$ coexpressed in $S f 9$ cells with ATX3-190 or ATX3-770 and reconstituted into planar lipid bilayers. Responses to application of $100 \mathrm{nM}$ $\operatorname{Ins}_{3}$ and $2 \mu \mathrm{m} I n s P_{3}$ are shown. Each current trace corresponds to $10 \mathrm{~s}$ ( 2 s for expanded traces) of current recording from the same experiment. $\boldsymbol{H}, \boldsymbol{K}$, The average Ins $P_{3} R 1$ open probability $\left(P_{0}\right)$ was calculated for a $5 \mathrm{~s}$ window of time and plotted for the duration of an experiment for Ins $P_{3} R 1$ coexpressed with ATX3-19Q or ATX3-77Q. The times of $100 \mathrm{~nm}$ and $2 \mu \mathrm{m}$ Ins $P_{3}$ additions to the bilayer are shown above the $P_{0}$ plot. Data from the same experiment are shown on $\boldsymbol{G}$ and $\boldsymbol{H}$, and $\boldsymbol{I}$ and $\boldsymbol{K}$. Similar results were obtained in four independent experiments with ATX3-190 and six independent experiments with ATX3-77Q.

induced much larger $\mathrm{Ca}^{2+}$ responses in hF-SCA3 cells than in control hF cells (Fig. $4 B, C$ ). On average, the amplitude of BKinduced $\mathrm{Ca}^{2+}$ responses was equal to $318 \pm 71 \mathrm{nM} \mathrm{Ca}^{2+}(n=43)$ in control hF cells and $573 \pm 108 \mathrm{nM} \mathrm{Ca}^{2+}(n=37)$ in hF-SCA3 cells, which was significantly higher $(p<0.05)$. From these experiments, we concluded that expression of mutant human ataxin-3 proteins has potentiating effect on $\mathrm{InsP}_{3} \mathrm{R}$-mediated $\mathrm{Ca}^{2+}$ release in SCA3 patient fibroblasts, consistent with our analysis of $\mathrm{Ca}^{2+}$ signals in cultured rat MSN transfected with mutant ATX ${ }^{\exp }$ (Fig. 3).

\section{Mutant ataxin-3 associates with $\operatorname{Ins} \mathrm{P}_{3} \mathrm{R} 1$ in vivo}

To establish a relevance of our findings for SCA3 pathogenesis in vivo, we focused on analysis of SCA3-YAC-84Q mouse model (Cemal et al., 2002). The SCA3-YAC-84Q mice used in these studies have been recreated by in vitro fertilization from a frozen 
sperm (for details, see Materials and Methods). In the first series of experiments, we assessed distribution of ataxin-3 protein in brains from 10- to 12-month-old SCA3YAC-84Q mice and 10- to 14-month-old SCA3-YAC-15Q mice (Cemal et al., 2002). The brain slices from different brain regions were stained with anti-Atx3 mouse monoclonal antibodies (Fig. 5) or humanspecific anti-ATX3 affinity-purified rabbit polyclonal antibodies (Paulson et al., 1997a) (supplemental Fig. 2, available at www.jneurosci.org as supplemental material). Very similar staining pattern was observed in both cases. We observed that the pattern of ATX3-84Q transgene expression and nuclear accumulation in the aging SCA3-YAC-84Q mouse brains corresponded closely with the regions most severely affected in SCA3 patients, with abundant nuclear accumulation of ataxin-3 in $\mathrm{Pn}, \mathrm{SN}$, and dentate nuclei (Lat) regions (Fig. 5; supplemental Fig. 2, available at www.jneurosci.org as supplemental material). In contrast, nuclear accumulation of ataxin-3 was not detected in striatum $(\mathrm{CPu})$, cortex, and hippocampus (Fig. 5; supplemental Fig. 2, available at www.jneurosci.org as supplemental material) (data not shown), which are the brain regions relatively spared in MJD/SCA3 patients (Stevanin et al., 2000). In SCA3YAC-15Q mouse brains, ataxin-3 protein was predominantly cytosolic and did not accumulate in the nucleus (Fig. 5; supplemental Fig. 2, available at www.jneurosci. org as supplemental material). Similarly, ataxin-3 was predominantly cytosolic in neurons from 3-month-old SCA3-YAC84Q mouse brains (data not shown). Therefore, we reasoned that the accumulation of ataxin-3 in aging SCA3-YAC$84 \mathrm{Q}$ mouse brains is a late event in the process of SCA3 pathogenesis, which may serve as an indication of the "stressed neurons." Nuclear accumulation of ataxin-3 does not appear to be required for abnormal $\mathrm{Ca}^{2+}$ signaling and most likely reflects pathological processes occurring at end stage of neuronal pathogenesis.

To determine whether ATX ${ }^{\exp }$ forms complex with $\operatorname{InsP}_{3} \mathrm{R} 1$ in vivo, we performed a series of experiments with cortical lysates from wild-type and SCA3-YAC$84 \mathrm{Q}$ mouse brains. The expression of ataxin-3 in these cortical lysates was analyzed by anti-Atx 3 monoclonal antibodies. Only wild-type mouse Atx3 was detected in cortical lysates from wild-type mouse brains (Fig. 6A). In contrast, both endogenous wild-type Atx3 and transgenic mutant ATX3-84Q were detected in cortical lysates from SCA3-YAC-84Q mouse

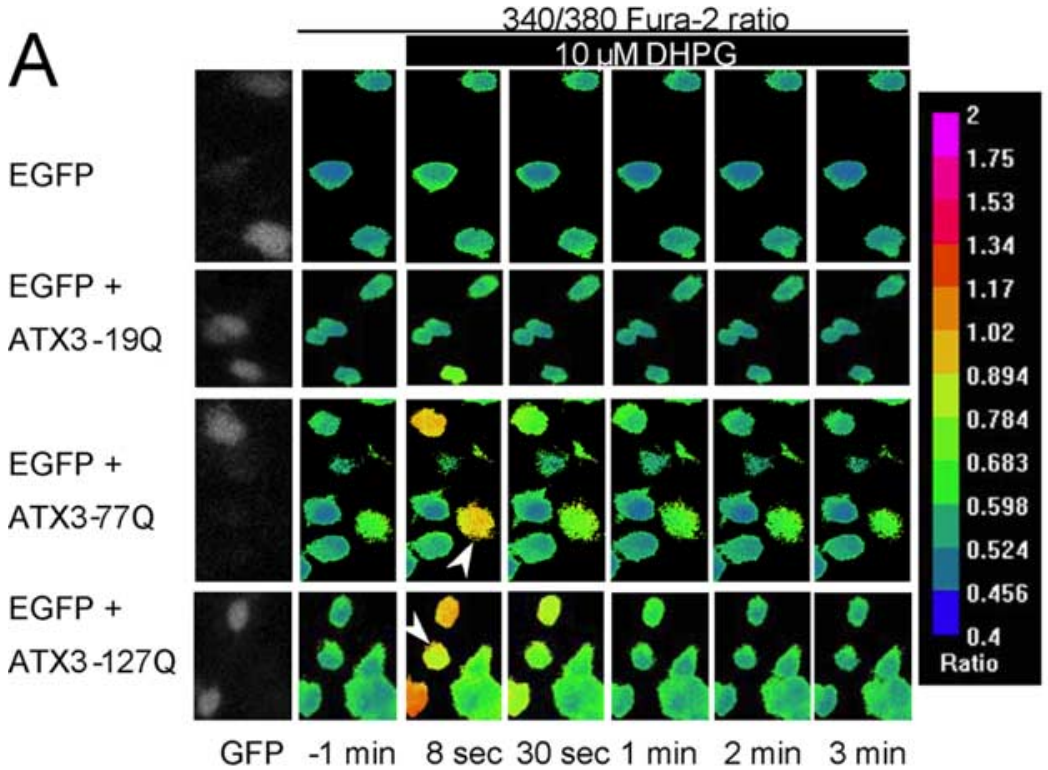

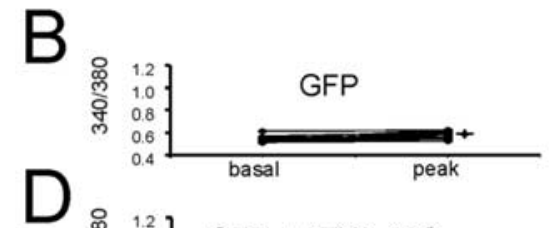

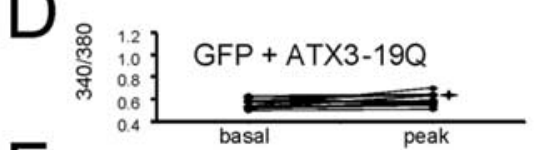

$\mathrm{F}$

$$
\text { - }
$$
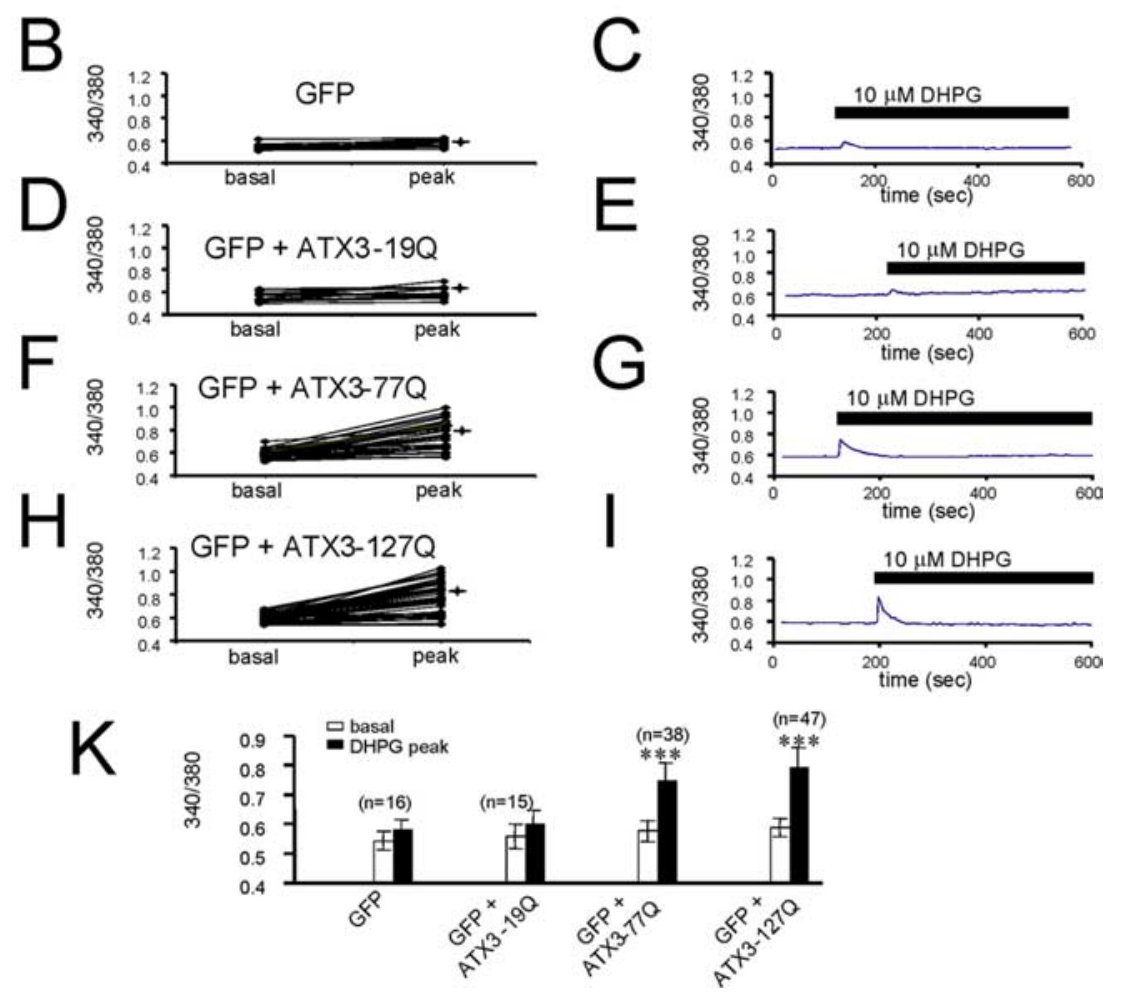

Figure 3. Effects of ataxin-3 on DHPG-induced $\mathrm{Ca}^{2+}$ release in MSN. A, Representative images showing fura-2340/380 ratios in transfected rat MSNs. The pseudocolor calibration scale for 340/380 ratios is shown on the right. Ratio recordings are shown for $10 \mu \mathrm{M}$ DHPG-induced Ca ${ }^{2+}$ transients in MSNs transfected with EGFP (first row), EGFP plus ATX3-19Q (second row), EGFP plus ATX3-77Q (third row), and EGFP plus ATX3-127Q (fourth row). The recordings were performed in Ca ${ }^{2+}$-free ACSF containing 100 $\mu$ M EGTA. GFP images (first column) were captured before $\mathrm{Ca}^{2+}$ imaging to identify transfected cells. The $340 / 380$ ratio images are shown for MSN neurons $1 \mathrm{~min}$ before (second column), and $8 \mathrm{~s}, 30 \mathrm{~s}, 1 \mathrm{~min}, 2 \mathrm{~min}$, and $3 \mathrm{~min}$ after application of $10 \mu \mathrm{m} \mathrm{DHPG}$ as indicated. We used ATX3:EGFP plasmids at a 3:1 ratio during transfections, which probably resulted in the expression of ATX3 in some GFP-negative MSNs. The GFP-negative cells that respond to $10 \mu \mathrm{M}$ DHPG in the third and fourth row (triangle arrow) are interpreted to be the neurons transfected with ATX3-77Q or ATX3-127Q plasmid alone. Only GFP-positive MSNs were considered for quantitative analyses. $\boldsymbol{B}, \boldsymbol{D}, \boldsymbol{F}, \boldsymbol{H}$, Basal and peak $340 / 380$ ratios are shown for individual MSN neurons transfected with EGFP (B), EGFP plus ATX3-19Q (D), EGFP plus ATX3-77Q (F), EGFP plus ATX3-1270 (H). The experiments were performed as described on $A$. The basal ratios were determined $1 \mathrm{~min}$ before DHPG application $(-1 \mathrm{~min})$. The peak ratios were measured from maximal signals observed within $30 \mathrm{~s}$ after DHPG application. The $340 / 380$ ratio traces for representative cells (marked *) are shown in $C$, $\boldsymbol{E}, \boldsymbol{G}$, and $\boldsymbol{I}$. Time of DHPG application is shown. Similar results were obtained in four independent transfections. $\boldsymbol{K}$, Summary of MSN Ca ${ }^{2+}$ imaging experiments with ATX3 constructs. Average basal and DHPG-evoked peak $340 / 380$ ratios from four independent transfections are shown as mean \pm SEM ( $n=$ number of cells). The peak ratios in MSNs transfected with EGFP plus ATX3-77Q and EGFP plus ATX3-1270 are significantly $\left({ }^{* * *} p<0.01\right.$, paired $t$ test) higher than the basal ratios in the same cells. 


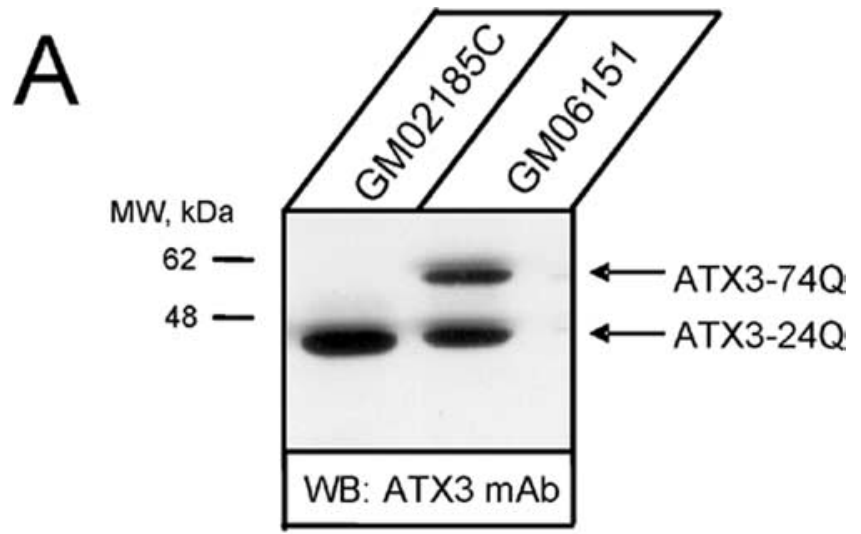

B
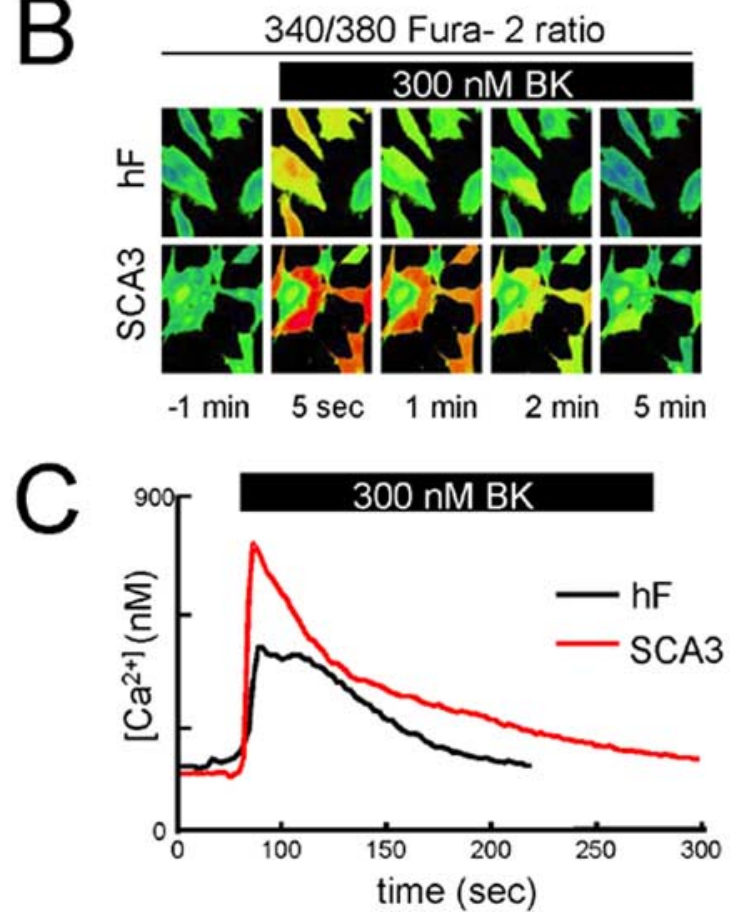

Figure 4. $\quad \mathrm{Ca}^{2+}$ signals in primary human fibroblasts from SCA3 patient. $A$, Ataxin-3 Western blots of lysates from control fibroblasts (GM02185C) and fibroblasts from SCA3 patient (GM06151). B , The representative fura-2 images of BK-induced $\mathrm{Ca}^{2+}$ responses are shown for control (hF) and SCA3 primary fibroblasts. $C$, The time course of BK-induced $\mathrm{Ca}^{2+}$ signals in representative experiments with control $(\mathrm{hF})$ and $\mathrm{SCA} 3$ primary fibroblasts.

brains (Fig. 6A). The cortical lysates from wild-type and SCA3YAC-84Q mice were used in immunoprecipitation experiments with anti-Atx 3 monoclonal antibodies and probed with monoclonal antibodies against $\operatorname{Ins}_{3} \mathrm{R} 1$. We found that anti-ataxin-3 $\mathrm{mAb}$ precipitated InsP $\mathrm{P}_{3} \mathrm{R} 1$ from $\mathrm{SCA} 3-\mathrm{YAC}-84 \mathrm{Q}$ cortical lysates but not from wild-type cortical lysates (Fig. $6 \mathrm{~B}$ ). Thus, in agreement with in vitro and in situ binding experiments (Fig. $1 \mathrm{~B}$; supplemental Fig. 1, available at www.jneurosci.org as supplemental material), Ins $\mathrm{P}_{3} \mathrm{R} 1$ specifically binds mutant $\mathrm{ATX}^{\exp }$ in vivo (Fig. 6B).

\section{Dantrolene alleviates motor coordination deficits in SCA3-YAC-84Q mice}

Biochemical and functional interactions between ATX $3^{\exp }$ and InsP $\mathrm{P}_{3} \mathrm{R} 1$ (Figs. 1-4, 6) suggested that deranged neuronal $\mathrm{Ca}^{2+}$ signaling may play a significant role in SCA3 pathogenesis. To test this hypothesis, we initiated a dantrolene trial in SCA3-YAC-84Q mice. Dantrolene is a skeletal muscle relaxant widely used in the clinic to treat malignant hyperthermia $(\mathrm{MH})$ and muscle spasticity (Krause et al., 2004). When used to treat $\mathrm{MH}$, dantrolene acts by inhibiting excessive $\mathrm{Ca}^{2+}$ release from sarcoplasmic reticulum in skeletal muscles. In neuronal cells, dantrolene has similar inhibitory effects on $\mathrm{Ca}^{2+}$ release from the endoplasmic reticulum (Makarewicz et al., 2003). One molecular target of dantrolene in muscle and neuronal cells is RyanR, an intracellular $\mathrm{Ca}^{2+}$ release channel. It has been also shown that azumolene, a structurally similar analog of dantrolene, inhibits store-operated $\mathrm{Ca}^{2+}$ entry (Zhao et al., 2006). Thus, dantrolene can be considered a general $\mathrm{Ca}^{2+}$ signaling stabilizer. In experiments with cultured neuronal cells and in animal models, dantrolene has been shown to have neuroprotective effect in a variety of excitotoxic paradigms (Frandsen and Schousboe, 1991; Berg et al., 1995; Mody and MacDonald, 1995; Wei and Perry, 1996; Guo et al., 1999; Niebauer and Gruenthal, 1999; Schneider et al., 2001; Popescu et al., 2002; Makarewicz et al., 2003). These results lead us to evaluate potential beneficial effects of dantrolene in SCA3-YAC-84Q mouse model.

In our studies, $100 \mu \mathrm{g}$ of dantrolene was resuspended in PBS and orally delivered to WT and SCA3-YAC-84Q (SCA3) mice twice a week starting at 2 months time point until all the mice were 12 months of age (Table 1, groups 2 and 4). The drug feeding was stopped after 12 month time point and was followed by a 1.5 month washout period. Control groups of WT and SCA3 mice were fed with PBS alone at the same time (Table 1, groups 1 and 3). The effectiveness of drug delivery was determined by 2 months of "drug dosage" trial. We found that, $30 \mathrm{~min}$ after feeding, dantrolene concentration in blood plasma was $1081.25 \pm$ $261.91 \mathrm{ng} / \mathrm{ml}$ and in brain it was $23.2 \pm 4.2 \mathrm{ng} / \mathrm{g}(67 \mathrm{~nm})$. Thus, we concluded that dantrolene accessed to the systemic circulation effectively from the gastrointestinal system, but penetrated blood-brain barrier poorly, which is in agreement with the previous findings in the animal model of cerebral ischemia in gerbils (Wei and Perry, 1996).

The behavioral assessment of all four groups of mice was performed by using "beam walk" assay (for details, see Materials and Methods for details). Basal beam-walking performance was determined before initiation of drug feeding when the mice were 2 months of age. The beam-walking data were collected at 2, 4, 7.5, 10,12 , and 13.5 (washout) months of age. As in our previous studies (Tang et al., 2007), three kinds of beams (17 mm round, $11 \mathrm{~mm}$ round, and $5 \mathrm{~mm}$ square) were used for testing. The "latency" and "number of foot slips" were determined on each beam. When results were analyzed, we found that control group of SCA3 mice (fed with PBS) exhibited a progressive impairment in beam-walking ability (longer beam traverse latencies and increased number of foot slips) with age and beam difficulty compared with control group of WT mice. The significant differences $(p<0.05)$ between beam performance of control SCA3 and control WT groups were observed at 10,12, and 13.5 months of age on $17 \mathrm{~mm}$ round beam (Fig. $7 A, B$ ); at $7.5,10,12$, and 13.5 months of age on $11 \mathrm{~mm}$ round beam and $5 \mathrm{~mm}$ square beam (Fig. 7C-F). Feeding dantrolene to WT mice had no significant effect on balance beam performance of these mice (Fig. 7A-F). However, feeding dantrolene to SCA3 mice improved their beam-walking performance, significantly $(p<0.05)$ shortening the latencies and decreasing the foot slip numbers (Fig. 7A-F). Significant differences $(p<0.05)$ of latency between SCA3 control group and dantrolene-fed SCA3 group were detected at 12 and 13.5 months of age on 17 round beam (Fig. 7A); at 10, 12, and 13.5 months of age on $11 \mathrm{~mm}$ round beam and $5 \mathrm{~mm}$ square 
beam (Fig. 7C,E). At 7.5, 10, and 12 month points, the number of foot slips of dantrolene-fed SCA3 mice on all three beams were almost identical with control WT mice (Fig. $7 B, D, F$ ). We noticed that, after dantrolene withdrawal, the performance of both WT and SCA3 groups of mice was impaired, with increased latencies and elevated numbers of foot slips (Fig. 7A-F). This phenomenon is most likely to be attributable to the removal of the sedative effect of dantrolene, which resulted in anxiousness of the mice. Despite this "withdrawal effect," dantrolene-fed SCA3 mice still performed better than control SCA3 mice in most tasks at the 13.5 month time point (Fig. 7A-F).

While conducting beam-walking assays, we observed that some aging mice exhibited periods of "crawling behavior" (defined as prolonged contact between the thorax and abdomen of the mice and beam surface, with the mice using forelimbs to drag themselves along the beam). Two mice in SCA3 control group crawled on 11 $\mathrm{mm}$ round and $5 \mathrm{~mm}$ square beams at 10 months time point, three mice in SCA3 control group crawled on $11 \mathrm{~mm}$ round beam and $5 \mathrm{~mm}$ square beam at 12 and 13.5 months of age, and two mice in SCA3 dantrolene-fed group crawled on $5 \mathrm{~mm}$ square beam at 12 and 13.5 months of age. Furthermore, one mouse in SCA3 control group fell off $5 \mathrm{~mm}$ square beam when tested at 12 and 13.5 month time points (Fig. $7 E, F$ ). In contrast, none of the mice in WT groups exhibited crawling behavior or fell off the beams at any age tested. The incidence of crawling behavior was consistent with a general performance of these mice in balance beam assay, with SCA3 control group performing the worst, dantrolene-fed SCA3 group performing better, and all the wild-type mice traversing the beams without crawling.

At the conclusion of beam-walking behavioral experiments (13.5 months of age), we assessed gait abnormalities in the four groups of mice by footprint pattern analysis (Fig. $8 \mathrm{~A}$ ). The footprint patterns were assessed quantitatively by the measurements of stride length and front/hind footprint overlap as we previously described (Tang et al., 2007). We found that the stride length of SCA3 control mice was very significantly $(p<0.001)$ shorter than WT control littermates (Fig. $8 B$ ). Dantrolene feeding significantly $(p<0.01)$ increased the stride length of SCA3 mice, but had no obvious effects on stride length of WT mice (Fig. $8 B$ ). We further found that front/hind footprint overlap was significantly higher in SCA3 control group than

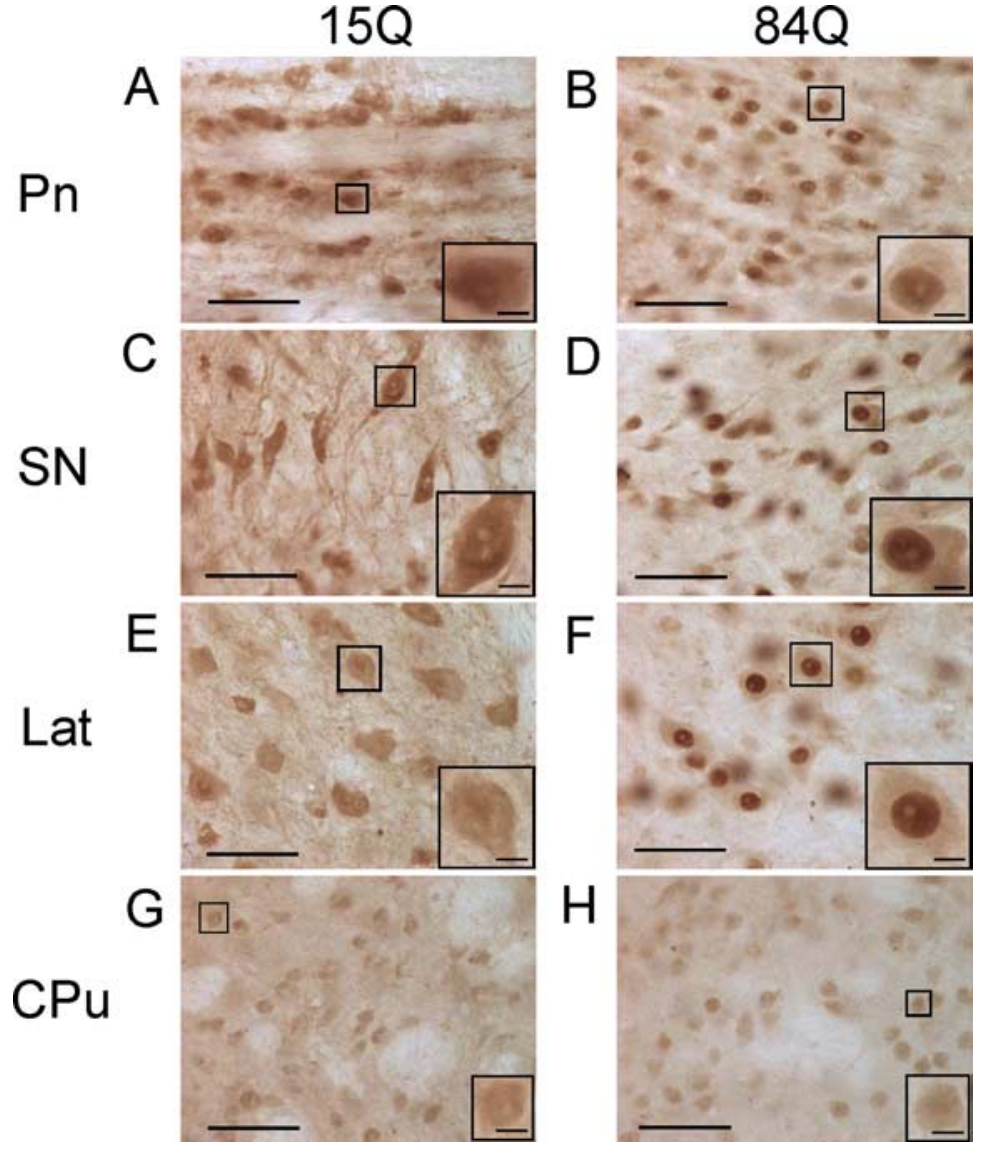

Figure 5. Expression and localization of ataxin-3 in aging SCA3-YAC- 150 and SCA3-YAC- 840 mouse brains. Expression and distribution of ataxin-3 protein were assessed in brains from 12-month-old SCA3-YAC-84Q mice and 14-month-old SCA3-YAC-150 mice. The coronal sections from these brains were stained with ataxin-3 monoclonal antibody and analyzed by light microscopy. ATX3 transgenes were found expressed ubiquitously in the mouse brains. In SCA3-YAC-84Q mice, we detected abundant nuclear accumulation of ataxin-3 in $\mathrm{Pn}(\boldsymbol{B}), \mathrm{SN}(\boldsymbol{D})$, and dentate nuclei (Lat) $(\boldsymbol{F})$. In SCA3-YAC-840 brains, nuclear accumulation of ataxin-3 was also abundantly detected in ventral tegmental area, globus pallidus, superior olivary complex, thalamus, and hypothalamus nuclei (data not shown). In contrast, ataxin-3 did not accumulate in striatum $(\mathrm{CPu})(\boldsymbol{H})$, cortex and hippocampus of aging SCA3-YAC-84Q brain (data not shown), which are brain regions relatively spared in MJD/SCA3 patients. In SCA3-YAC- 150 mice, ataxin-3 protein was expressed in a similar pattern but remained predominantly cytosolic and did not accumulate in the nucleus $(A, C, E, G)$. The magnified images of representative cells (framed by black squares) are shown as insets on each panel. Scale bars: outside squares, $50 \mu \mathrm{m}$; magnified images (inside squares), $5 \mu \mathrm{m}$. Similar results were obtained with two aging brains from SCA3-YAC- 150 and SCA3-YAC840 mice.
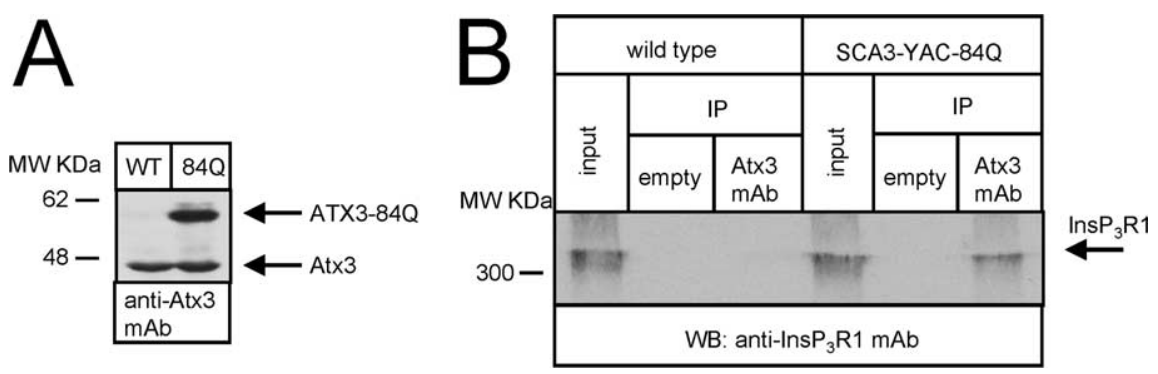

Figure 6. Association of ataxin-3 with $\operatorname{Ins}_{3} \mathrm{R} 1$ in vivo. $A$, The expression of endogenous and transgenic ataxin- 3 protein in the cortical lysates from WT and SCA3-YAC- 840 mice. Wild-type mouse brains only have endogenous wild-type Atx3, whereas SCA3-YAC-84Q mouse brains have both endogenous wild-type Atx3 and transgenic mutant ATX3-84Q. B, The cortical lysates from WT and SCA3-YAC-840 mice were precipitated by anti-ataxin-3 mAb and analyzed by Western blotting with anti-Ins $\mathrm{P}_{3} \mathrm{R} 1$ $\mathrm{mAb}$. Ins $\mathrm{P}_{3} \mathrm{R} 1$ was detected in samples precipitated from SCA3-YAC-84Q cortical lysates, but not from wild-type cortical lysates. Empty protein A/G PLUS-Agarose beads were used as negative control in the immunoprecipitation experiments. The input lanes contain 1/25 of the lysates used for IP experiments. 

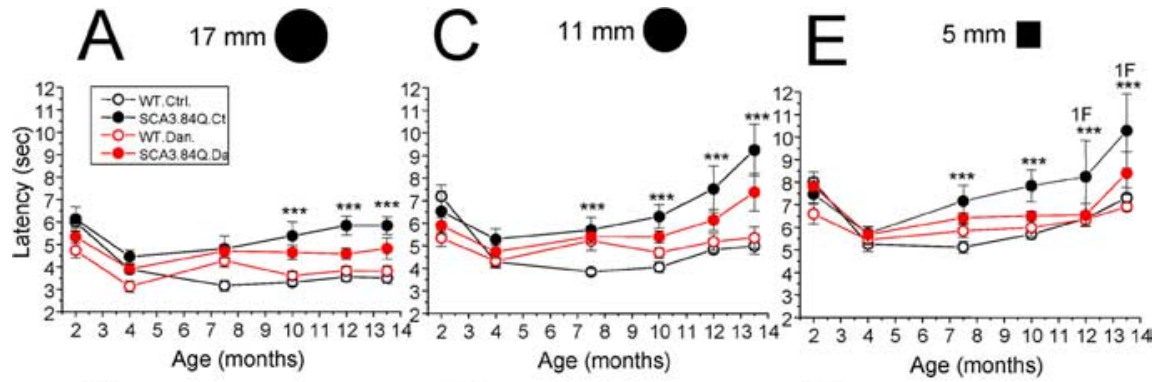

B
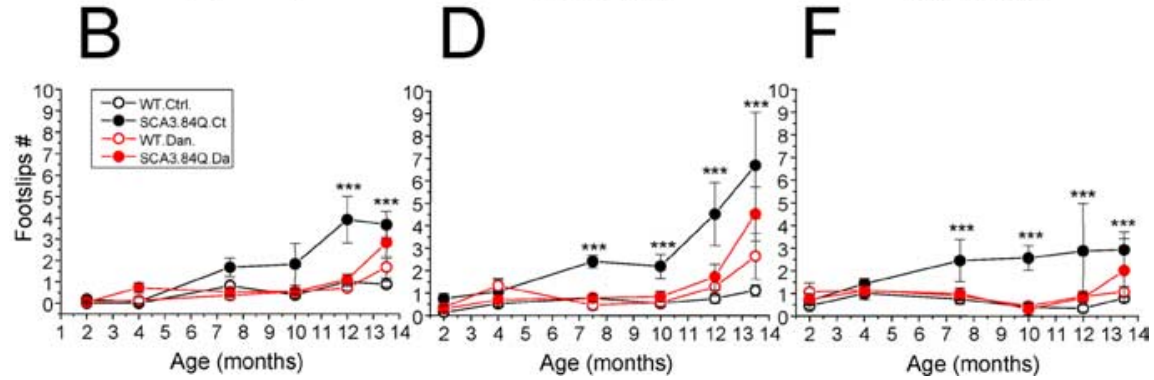

Figure 7. Motor coordination performance of WT and SCA3 mice in dantrolene trial. $\boldsymbol{A}-\boldsymbol{F}$, Beam walk assay. The average time to cross the beam $(\boldsymbol{A}, \boldsymbol{C}, \boldsymbol{E})$ and the average number of foot slips on the beam $(\boldsymbol{B}, \boldsymbol{D}, \boldsymbol{F})$ are shown for beam-walking experiments performed with $17 \mathrm{~mm}$ round plastic beam $(\boldsymbol{A}, \boldsymbol{B}), 11 \mathrm{~mm}$ round plastic beam $(\boldsymbol{C}, \boldsymbol{D})$, and $5 \mathrm{~mm}$ square wood beam $(\boldsymbol{E}, \boldsymbol{F})$. The data for WT control mice (open black circles), SCA3 control mice (filled black circles), WT mice fed with dantrolene (open red circles), and SCA3 mice fed with dantrolene (filled red circles) are shown as mean \pm SEM (for the number of mice in each group, see Table 1 ) at 2,4,7.5, 10,12, and 13.5 month (washout) time points. While counting the foot slips of the mice with "crawling behavior," we considered every step as one foot slip. ${ }^{* *} p<0.05$, significant differences between control SCA3 group and control WT group.

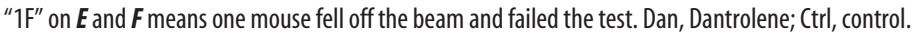
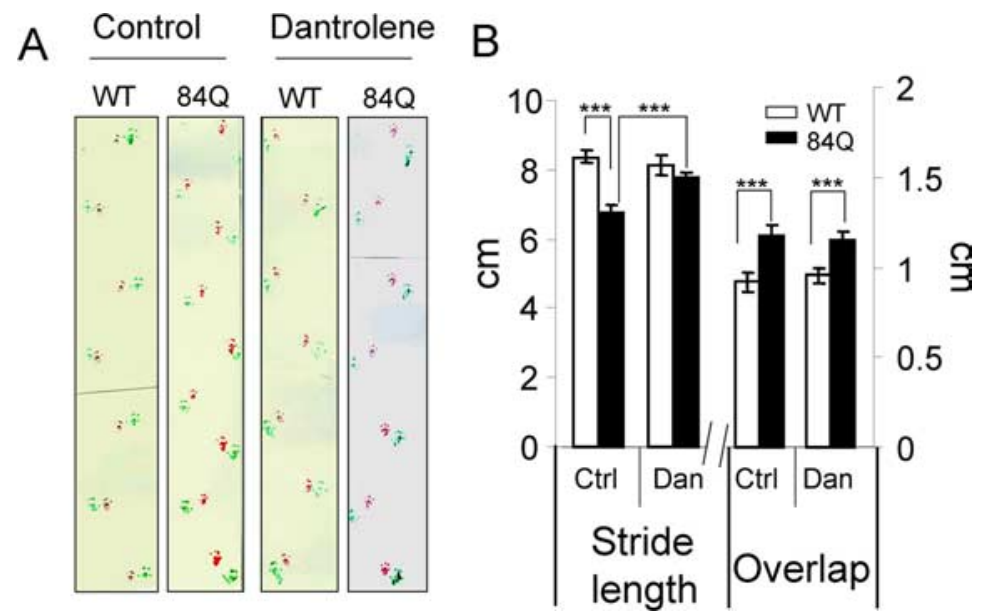

Figure 8. Gait analysis of WT and SCA3 mice in dantrolene trial. $A$, The footprint patterns of 13.5 -month-old SCA 3 and WT mice. The footprints for control and dantrolene groups are shown for both WT and SCA3 mice. B, Stride lengths and front/hind footprint overlaps of WT and SCA3 mice in dantrolene trial are shown as mean \pm SEM (for the number of mice in each group, see Table 1 ). Feeding dantrolene to SCA3 mice significantly $\left({ }^{* * *} p<0.001\right)$ increased the stride lengths but had no effect on front/hindpaw overlaps. Dan, Dantrolene; Ctrl, control.

in WT control group (Fig. 8 B). In contrast to stride length measurement, footprint overlap deficit was not rescued by feeding dantrolene to SCA3 mice (Fig. $8 B$ ).

\section{Dantrolene protects against neuronal loss in SCA3-YAC-84Q mice}

To further evaluate potential neuroprotective effects of dantrolene, at the conclusion of behavioral analysis (13.5 month time point), the brains from all four groups of experimental mice were removed from skull and weighed after transcardial perfusion. We found that the brains of control SCA3 mice (fed with PBS) weighted significantly less $(p<0.01)$ than the brains of control WT mice group (Fig. $9 A$, Table 1). Feeding dantrolene to WT mice had no significant effect on brain weight of these mice (Fig. 9A, Table 1), whereas the brain weight of SCA3 mice fed with dantrolene was higher than the brain weight of control SCA3 mice (Fig. 9A, Table 1), although the difference did not reach a level of statistical significance.

To obtain quantitative information about neuronal loss in the experimental mice, we performed stereological analysis of these brains. Our analysis was focused on $\mathrm{Pn}$ and $\mathrm{SN}$ regions, both of which severely affected in SCA3 patients (Stevanin et al., 2000). Our own experiments confirmed abundant accumulation of ATX384Q transgene in neurons from Pn and SN regions in brains from aging SCA3-YAC84Q mice (Fig. 5; supplemental Fig. 2, available at www.jneurosci.org as supplemental material). For stereological analysis, NeuN-positive neurons in Pn and THpositive neurons in $\mathrm{SN}$ were counted blindly with respect to the nature of slices (genotype and drug treatment). We focused on TH-positive neurons in $\mathrm{SN}$ as dopaminergic neurons are most severely affected in SCA3 patients (Stevanin et al., 2000), and our own analysis demonstrated that Atx3-84Q transgene is primarily expressed in $\mathrm{SN}$ dopaminergic neurons of SCA3-YAC-84Q mice (data not shown). By stereological analysis, we determined that control SCA3 mice (fed with PBS) showed significant neuronal loss in $\mathrm{Pn}$ $(p<0.05)$ and $\mathrm{SN}(p<0.01)$ when compared with control WT mice (Fig. $9 B, C$; Table 1). We further found that feeding of dantrolene had no significant effect on Pn and SN neuronal counts in WT mice; however, dantrolene feeding significantly increased Pn and SN neuronal counts $(p<$ 0.01 ) in SCA3 mice (Fig. 9B, $C$; Table 1). Our results indicated that feeding with dantrolene protected most $\mathrm{Pn}$ and $\mathrm{SN}$ neurons from cell death in brains of aging SCA3 mice.

\section{Discussion}

The causes of neurodegeneration in SCA3 and other $\operatorname{poly}(\mathrm{Q})$-expansion disorders are poorly understood. Similar to other poly(Q)-expansion disorders, mutant ataxin-3 forms nuclear aggregates (Fig. 5), and formation of these aggregates has been proposed to be toxic to the affected neurons (Paulson et al., 1997b; Perez et al., 1999). The nuclear toxicity of ataxin-3 has been supported by recent genetic experiments with transgenic mouse model of SCA3 (Bichelmeier et al., 2007). Consistent with the presence of Josephin domain and ubiquitin-interactions motifs, ataxin-3 binds to polyubiquitylated proteins and displays deubiquitylating activity in vitro (Burnett et al., 2003; Burnett and Pittman, 2005). In agreement 
A

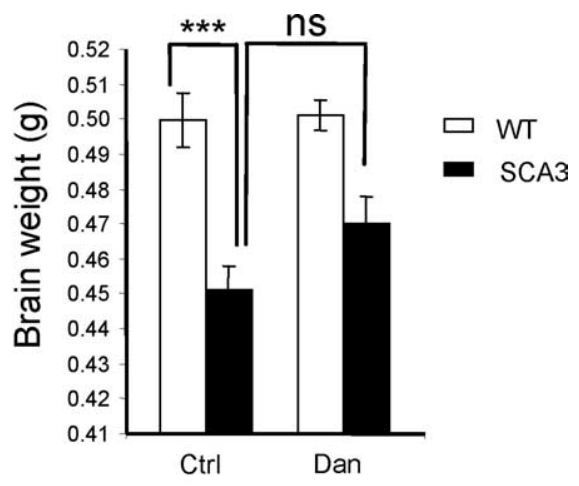

B

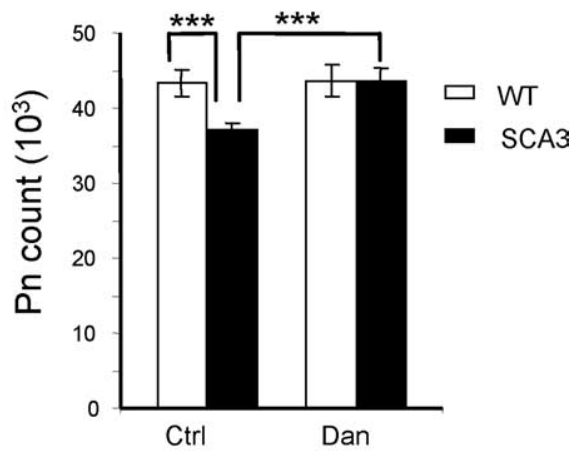

C

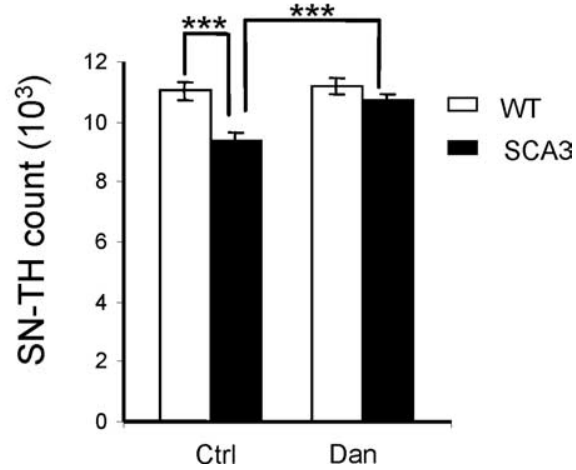

Figure 9. Neuroanatomical analysis of WT and SCA3 mice in dantrolene trial. $\boldsymbol{A}$, Average brain weight of 13.5-month-old WT and SCA3 mice. The brain weight of control SCA3 mice is significantly reduced compared with control WT group $(p<0.01)$. The brain weight of SCA3 mice fed with dantrolene is higher than control SCA3 mice, but the difference is not statistically significant. B, Average Pn neuronal counts of 13.5-month-old WT and SCA3 mice are shown as mean \pm SEM (for the number of mice in each group, see Table 1). Control SCA3 mice showed significant Pn neuronal loss $\left({ }^{* * *} p<0.05\right)$ compared with control WT mice. SCA3 mice fed with dantrolene exhibited significantly $\left({ }^{* * *} p<0.01\right)$ increased Pn neuronal counts compared with control SCA3 mice. C, Average SN neuronal counts of TH-positive neurons from 13.5-month-old WT and SCA3 mice are shown as mean \pm SEM (for the number of mice in each group, see Table 1). The SN-TH neuronal number in control SCA3 mice is significantly lower $\left({ }^{* * *} p<0.01\right)$ than in control WT mice. In SCA3 mice fed with dantrolene, the SN-TH neuronal counts are significantly $\left({ }^{* * *} p<0.01\right)$ increased when compared with control SCA3 mice. Dan, Dantrolene; $\mathrm{Ctrl}$, control.

with defects in ubiqutin-proteasomal pathway, impaired proteasomal function has been implicated in SCA3 pathogenesis (Chai et al., 1999). Results of our studies indicate that, in addition to forming "toxic aggregates" and causing "proteasomal deficiency," mutant ataxin-3 is also able to destabilize neuronal $\mathrm{Ca}^{2+}$ signaling. We found that mutant ataxin-3 directly binds to the InsP ${ }_{3} \mathrm{R} 1$ (Figs. $1 A, B, 6 B$; supplemental Fig. 1, available at www. jneurosci.org as supplemental material), which may make Ins $\mathrm{P}_{3} \mathrm{R} 1$ "gate" easier to open, and thus increases the sensitivity of InsP $\mathrm{P}_{3} \mathrm{R} 1$ to activation by $\mathrm{Ins}_{3}$ in vitro and in cells (Figs. $2-4$ ). The mechanism of $\mathrm{ATX}^{\text {exp }}$ effects on $\mathrm{Ins}_{3} \mathrm{R} 1$ and $\mathrm{Ca}^{2+}$ signaling in this study is similar to the actions of $\mathrm{Htt}^{\text {exp }}$ we described previously (Tang et al., 2003), and supports the assumption that many poly(Q)-expansion disorders share common pathogenic mechanisms (Cummings and Zoghbi, 2000; Gusella and MacDonald, 2000; Zoghbi and Orr, 2000).

Based on the biochemical and functional interactions between mutant ataxin-3 and $\operatorname{Ins}_{3} \mathrm{R} 1$ (Figs. 1-4, 6), we reasoned that deranged neuronal $\mathrm{Ca}^{2+}$ signaling may contribute to SCA3 pathogenesis. To test this hypothesis, we set out to evaluate the potential benefits of a $\mathrm{Ca}^{2+}$ signaling inhibitor in SCA3-YAC84Q animal model (Cemal et al., 2002). The only specific membranepermeable inhibitor of $\operatorname{Ins}_{3} \mathrm{R} 1$ is xestospongin C (Gafni et al., 1997). However, xestospongin $C$ is not stable in vivo and not appropriate for animal trials. Thus, instead of targeting $\operatorname{Ins} \mathrm{P}_{3} \mathrm{R}$ for our animal studies, we decided to target another intracellular $\mathrm{Ca}^{2+}$ release channel, the RyanR. RyanRs are widely expressed in the nervous system (Giannini et al., 1995). The $\mathrm{Ca}^{2+}$ release from intracellular stores in neurons often consists of $\mathrm{InsP}_{3}$-induced calcium release (IICR) mediated by $\mathrm{InsP}_{3} \mathrm{R}$ and calcium-induced calcium release (CICR) triggered by the openings of RyanR (Berridge, 1998; Verkhratsky, 2005). Furthermore, RyanR-mediated CICR also serves to amplify $\mathrm{Ca}^{2+}$ signals resulting from influx via NMDAR and voltage-gated $\mathrm{Ca}^{2+}$ channels (Berridge, 1998; Verkhratsky, 2005). Therefore, we reasoned that pharmacological inhibition of RyanR may compensate for enhanced activity of $\mathrm{Ins}_{3} \mathrm{R} 1$ and result in neuroprotective effects in SCA3 mouse model.

To block neuronal RyanR, we selected dantrolene, a clinically relevant inhibitor of RyanR (Krause et al., 2004). It has been also shown that azumolene, a structurally similar analog of dantrolene, inhibits store-operated $\mathrm{Ca}^{2+}$ entry (Zhao et al., 2006). Thus, dantrolene can be considered a general $\mathrm{Ca}^{2+}$ signaling stabilizer. In previous experiments with cultured neuronal cells and in animal models, dantrolene has been shown to have neuroprotective effect in a variety of excitotoxic paradigms (Frandsen and Schousboe, 1991; Berg et al., 1995; Mody and MacDonald, 1995; Wei and Perry, 1996; Guo et al., 1999; Niebauer and Gruenthal, 1999; Schneider et al., 2001; Popescu et al., 2002; Makarewicz et al., 2003). Thus, we set out to investigate potential neuroprotective effects of dantrolene in the mouse model of SCA3. For our trial, we choose to fed the mice with $5 \mathrm{mg} / \mathrm{kg}$ dantrolene, which is the typical dosage of oral administration of dantrolene used in humans $\left(4-8 \mathrm{mg} \cdot \mathrm{kg}^{-1} \cdot \mathrm{d}^{-1}\right.$ ) (Ward et al., 1986). Pharmacokinetic studies of dantrolene demonstrated that, in healthy conscious volunteers, intravenous administration of dantrolene $2.4 \mathrm{mg} / \mathrm{kg}$ results in plasma concentration of 4.2 $\mu \mathrm{g} / \mathrm{ml}$ (Krause et al., 2004), which is $12.5 \mu \mathrm{M}$. In animal studies, dantrolene was used in rat or mice at the dosage of 5,10 , or even 25-50 mg/kg (Berg et al., 1995; Wei and Perry, 1996; Niebauer and Gruenthal, 1999; Schneider et al., 2001; Popescu et al., 2002; Acikel et al., 2005). Both 25 and $50 \mathrm{mg} / \mathrm{kg}$ caused the death of animals. Considering the long-term trial, we selected a "low end" dose of $5 \mathrm{mg} / \mathrm{kg}$ with twice per week drug delivery. Dantrolene is a potent muscle relaxant and has sedative effects, and we indeed noticed that the mice were much less active for several hours after dantrolene feeding. However, none of the mice died during the 14 months trial and all mice could recover within several hours after dantrolene feeding and start to behave normally.

In agreement with the previous studies (Wei and Perry, 1996), we found that dantrolene crossed the brain-blood barrier poorly, reaching concentration of only $67 \mathrm{~nm}$ in the mouse brains (30 min after feeding). We reasoned that dantrolene is a highly lipophilic substance that may accumulate in the membranes, 
which makes its membrane concentration high enough to block RyanR and store-operated calcium (SOC) and to provide protective effects. Consistent with this interpretation, neuroprotective effects of peripherally administered dantrolene were observed in whole-animal models of cerebral ischemia (Wei and Perry, 1996) and in studies of kainic acid-induced excitotoxicity paradigm (Berg et al., 1995; Niebauer and Gruenthal, 1999; Schneider et al., 2001; Popescu et al., 2002). Thus, it appears that concentrations of dantrolene reached in the brain in these studies were sufficient to block neuronal RyanR and SOC and to cause neuroprotective effects. Similarly, in our experiments we discovered that feeding SCA3-YAC-84Q mice with $5 \mathrm{mg} / \mathrm{kg}$ dantrolene significantly improved their performance in motor coordination assay (Figs. 7 , 8). More importantly, there was significantly less neuronal loss in pontine nuclei and substantia nigra regions of the mice fed with dantrolene (Fig. 9, Table 1). This indicates that dantrolene is neuroprotective and supports the hypothesis that deranged calcium signaling may play a significant role in the pathogenesis of SCA3.

In our study, we established the connection between deranged intracellular $\mathrm{Ca}^{2+}$ signaling and neurodegeneration in SCA3. Together with our previous studies of HD (Tang et al., 2003, 2005, 2007; Bezprozvanny and Hayden, 2004; Wu et al., 2006), these results suggest that abnormal neuronal $\mathrm{Ca}^{2+}$ signaling may play a role in pathogenesis of many polyglutamine expansion disorders. Short-term delivery of dantrolene has been previously demonstrated to be neuroprotective in acute excitotoxicity paradigms, such as cerebral ischemia (Wei and Perry, 1996) and kainic acid injection model (Berg et al., 1995; Niebauer and Gruenthal, 1999; Schneider et al., 2001; Popescu et al., 2002). Here, for the first time, we demonstrated protective effects of long-term treatment with dantrolene in an animal model of a chronic neurodegenerative disorder. Also, for the first time, we demonstrated that a clinically relevant drug exerts beneficial effects in an animal model of SCA3. Our results indicate that calcium-signaling stabilizers such as dantrolene should be considered as potential therapeutics for the treatment of SCA3 patients and possibly other neurodegenerative disorders.

\section{References}

Acikel M, Buyukokuroglu ME, Erdogan F, Aksoy H, Bozkurt E, Senocak H (2005) Protective effects of dantrolene against myocardial injury induced by isoproterenol in rats: biochemical and histological findings. Int J Cardiol 98:389-394.

Berg M, Bruhn T, Frandsen A, Schousboe A, Diemer NH (1995) Kainic acid-induced seizures and brain damage in the rat: role of calcium homeostasis. J Neurosci Res 40:641-646.

Berridge MJ (1998) Neuronal calcium signaling. Neuron 21:13-26.

Bezprozvanny I, Hayden MR (2004) Deranged neuronal calcium signaling and Huntington disease. Biochem Biophys Res Commun 322:1310-1317.

Bezprozvanny I, Watras J, Ehrlich BE (1991) Bell-shaped calcium-response curves of Ins $(1,4,5) \mathrm{P}_{3}-$ and calcium-gated channels from endoplasmic reticulum of cerebellum. Nature 351:751-754.

Bichelmeier U, Schmidt T, Hübener J, Boy J, Rüttiger L, Häbig K, Poths S, Bonin M, Knipper M, Schmidt WJ, Wilbertz J, Wolburg H, Laccone F, Riess O (2007) Nuclear localization of ataxin-3 is required for the manifestation of symptoms in SCA3: in vivo evidence. J Neurosci 27:7418-7428.

Burnett B, Li F, Pittman RN (2003) The polyglutamine neurodegenerative protein ataxin- 3 binds polyubiquitylated proteins and has ubiquitin protease activity. Hum Mol Genet 12:3195-3205.

Burnett BG, Pittman RN (2005) The polyglutamine neurodegenerative protein ataxin 3 regulates aggresome formation. Proc Natl Acad Sci U S A 102:4330-4335.

Cemal CK, Carroll CJ, Lawrence L, Lowrie MB, Ruddle P, Al-Mahdawi S, King RH, Pook MA, Huxley C, Chamberlain S (2002) YAC transgenic mice carrying pathological alleles of the MJD1 locus exhibit a mild and slowly progressive cerebellar deficit. Hum Mol Genet 11:1075-1094.

Chai Y, Koppenhafer SL, Shoesmith SJ, Perez MK, Paulson HL (1999) Evidence for proteasome involvement in polyglutamine disease: localization to nuclear inclusions in SCA3/MJD and suppression of polyglutamine aggregation in vitro. Hum Mol Genet 8:673-682.

Coutinho P, Andrade C (1978) Autosomal dominant system degeneration in Portuguese families of the Azores Islands. A new genetic disorder involving cerebellar, pyramidal, extrapyramidal and spinal cord motor functions. Neurology 28:703-709.

Cummings CJ, Zoghbi HY (2000) Trinucleotide repeats: mechanisms and pathophysiology. Annu Rev Genomics Hum Genet 1:281-328.

Frandsen A, Schousboe A (1991) Dantrolene prevents glutamate cytotoxicity and $\mathrm{Ca}^{2+}$ release from intracellular stores in cultured cerebral cortical neurons. J Neurochem 56:1075-1078.

Gafni J, Munsch JA, Lam TH, Catlin MC, Costa LG, Molinski TF, Pessah IN (1997) Xestospongins: potent membrane permeable blockers of the inositol 1,4,5-trisphosphate receptor. Neuron 19:723-733.

Giannini G, Conti A, Mammarella S, Scrobogna M, Sorrentino V (1995) The ryanodine receptor/calcium channel genes are widely and differentially expressed in murine brain and peripheral tissues. J Cell Biol 128:893-904.

Guo Q, Fu W, Sopher BL, Miller MW, Ware CB, Martin GM, Mattson MP (1999) Increased vulnerability of hippocampal neurons to excitotoxic necrosis in presenilin-1 mutant knock-in mice. Nat Med 5:101-106.

Gusella JF, MacDonald ME (2000) Molecular genetics: unmasking polyglutamine triggers in neurodegenerative disease. Nat Rev Neurosci $1: 109-115$.

Kawaguchi Y, Okamoto T, Taniwaki M, Aizawa M, Inoue M, Katayama S, Kawakami H, Nakamura S, Nishimura M, Akiguchi I, Kimura J, Narumiya S, Kakizuka A (1994) CAG expansions in a novel gene for Machado-Joseph disease at chromosome 14q32.1. Nat Genet 8:221-228.

Kaznacheyeva E, Lupu VD, Bezprozvanny I (1998) Single-channel properties of inositol $(1,4,5)$-trisphosphate receptor heterologously expressed in HEK-293 cells. J Gen Physiol 111:847-856.

Krause T, Gerbershagen MU, Fiege M, Weisshorn R, Wappler F (2004) Dantrolene-a review of its pharmacology, therapeutic use and new developments. Anaesthesia 59:364-373.

Makarewicz D, Ziemińska E, Łazarewicz JW (2003) Dantrolene inhibits NMDA-induced $45 \mathrm{Ca}$ uptake in cultured cerebellar granule neurons. Neurochem Int 43:273-278.

Mody I, MacDonald JF (1995) NMDA receptor-dependent excitotoxicity: the role of intracellular $\mathrm{Ca}^{2+}$ release. Trends Pharmacol Sci 16:356-359.

Nelson O, Tu H, Lei T, Bentahir M, de Strooper B, Bezprozvanny I (2007) Familial Alzheimer disease-linked mutations specifically disrupt $\mathrm{Ca}^{2+}$ leak function of presenilin 1. J Clin Invest 117:1230-1239.

Nicastro G, Menon RP, Masino L, Knowles PP, McDonald NQ, Pastore A (2005) The solution structure of the Josephin domain of ataxin-3: structural determinants for molecular recognition. Proc Natl Acad Sci U S A 102:10493-10498.

Niebauer M, Gruenthal M (1999) Neuroprotective effects of early vs. late administration of dantrolene in experimental status epilepticus. Neuropharmacology 38:1343-1348.

Paulson HL, Das SS, Crino PB, Perez MK, Patel SC, Gotsdiner D, Fischbeck KH, Pittman RN (1997a) Machado-Joseph disease gene product is a cytoplasmic protein widely expressed in brain. Ann Neurol 41:453-462.

Paulson HL, Perez MK, Trottier Y, Trojanowski JQ, Subramony SH, Das SS, Vig P, Mandel JL, Fischbeck KH, Pittman RN (1997b) Intranuclear inclusions of expanded polyglutamine protein in spinocerebellar ataxia type 3. Neuron 19:333-344.

Perez MK, Paulson HL, Pittman RN (1999) Ataxin-3 with an altered conformation that exposes the polyglutamine domain is associated with the nuclear matrix. Hum Mol Genet 8:2377-2385.

Popescu BO, Oprica M, Sajin M, Stanciu CL, Bajenaru O, Predescu A, Vidulescu C, Popescu LM (2002) Dantrolene protects neurons against kainic acid induced apoptosis in vitro and in vivo. J Cell Mol Med 6:555-569.

Scheel H, Tomiuk S, Hofmann K (2003) Elucidation of ataxin-3 and ataxin-7 function by integrative bioinformatics. Hum Mol Genet 12:2845-2852.

Schneider I, Reverse D, Dewachter I, Ris L, Caluwaerts N, Kuiperi C, Gilis M, Geerts H, Kretzschmar H, Godaux E, Moechars D, Van Leuven F, Herms 
J (2001) Mutant presenilins disturb neuronal calcium homeostasis in the brain of transgenic mice, decreasing the threshold for excitotoxicity and facilitating long-term potentiation. J Biol Chem 276:11539-11544.

Stevanin G, Dürr A, Brice A (2000) Clinical and molecular advances in autosomal dominant cerebellar ataxias: from genotype to phenotype and physiopathology. Eur J Hum Genet 8:4-18.

Tang TS, Tu H, Chan EY, Maximov A, Wang Z, Wellington CL, Hayden MR, Bezprozvanny I (2003) Huntingtin and huntingtin-associated protein 1 influence neuronal calcium signaling mediated by inositol- $(1,4,5)$ triphosphate receptor type 1. Neuron 39:227-239.

Tang TS, Slow E, Lupu V, Stavrovskaya IG, Sugimori M, Llinás R, Kristal BS, Hayden MR, Bezprozvanny I (2005) Disturbed $\mathrm{Ca}^{2+}$ signaling and apoptosis of medium spiny neurons in Huntington's disease. Proc Natl Acad Sci U S A 102:2602-2607.

Tang TS, Chen X, Liu J, Bezprozvanny I (2007) Dopaminergic signaling and striatal neurodegeneration in Huntington's disease. J Neurosci 27:7899-7910.

Tu H, Miyakawa T, Wang Z, Glouchankova L, Iino M, Bezprozvanny I (2002) Functional characterization of the type 1 inositol 1,4,5trisphosphate receptor coupling domain SII $(+/-)$ splice variants and the opisthotonos mutant form. Biophys J 82:1995-2004.

Tu H, Wang Z, Nosyreva E, De Smedt H, Bezprozvanny I (2005a) Functional characterization of mammalian inositol 1,4,5-trisphosphate receptor isoforms. Biophys J 88:1046-1055.
Tu H, Wang Z, Bezprozvanny I (2005b) Modulation of mammalian inositol 1,4,5-trisphosphate receptor isoforms by calcium: a role of calcium sensor region. Biophys J 88:1056-1069.

Verkhratsky A (2005) Physiology and pathophysiology of the calcium store in the endoplasmic reticulum of neurons. Physiol Rev 85:201-279.

Wang G, Sawai N, Kotliarova S, Kanazawa I, Nukina N (2000) Ataxin-3, the MJD1 gene product, interacts with the two human homologs of yeast DNA repair protein RAD23, HHR23A and HHR23B. Hum Mol Genet 9:1795-1803.

Ward A, Chaffman MO, Sorkin EM (1986) Dantrolene. A review of its pharmacodynamic and pharmacokinetic properties and therapeutic use in malignant hyperthermia, the neuroleptic malignant syndrome and an update of its use in muscle spasticity. Drugs 32:130-168.

Wei H, Perry DC (1996) Dantrolene is cytoprotective in two models of neuronal cell death. J Neurochem 67:2390-2398.

Wu J, Tang T, Bezprozvanny I (2006) Evaluation of clinically-relevant glutamate pathway inhibitors in in vitro model of Huntington's disease. Neurosci Lett 407:219-223.

Zhao X, Weisleder N, Han X, Pan Z, Parness J, Brotto M, Ma J (2006) Azumolene inhibits a component of store-operated calcium entry coupled to the skeletal muscle ryanodine receptor. J Biol Chem 281:33477-33486.

Zoghbi HY, Orr HT (2000) Glutamine repeats and neurodegeneration. Annu Rev Neurosci 23:217-247. 